\title{
Hydrogen assisted catalytic biomass pyrolysis. Effect of temperature and pressure
}

\author{
Stummann, M.Z.; Høj, M.; Schandel, C. B.; Hansen, A. B.; Wiwel, P.; Gabrielsen, J.; Jensen, P. A.;
} Jensen, A. D.

Published in:

Biomass and Bioenergy

Link to article, DOI:

10.1016/j.biombioe.2018.04.012

Publication date:

2018

Document Version

Peer reviewed version

Link back to DTU Orbit

Citation $(A P A)$ :

Stummann, M. Z., Høj, M., Schandel, C. B., Hansen, A. B., Wiwel, P., Gabrielsen, J., Jensen, P. A., \& Jensen, A. D. (2018). Hydrogen assisted catalytic biomass pyrolysis. Effect of temperature and pressure. Biomass and Bioenergy, 115, 97-107. https://doi.org/10.1016/j.biombioe.2018.04.012

\section{General rights}

Copyright and moral rights for the publications made accessible in the public portal are retained by the authors and/or other copyright owners and it is a condition of accessing publications that users recognise and abide by the legal requirements associated with these rights.

- Users may download and print one copy of any publication from the public portal for the purpose of private study or research.

- You may not further distribute the material or use it for any profit-making activity or commercial gain

- You may freely distribute the URL identifying the publication in the public portal 
1 Hydrogen assisted catalytic biomass

2 pyrolysis. Effect of temperature and

${ }_{3}$ pressure

4 M.Z. Stummann ${ }^{a}$, M. Høj ${ }^{a}$, C. B. Schandel ${ }^{a}$, A. B. Hansen ${ }^{b}$, P. Wiwel ${ }^{b}$, J. Gabrielsen $^{b}$, P. A. Jensen ${ }^{a}$, A. D.

5 Jensen ${ }^{a^{*}}$

$6{ }^{a}$ Department of Chemical and Biochemical Engineering, Technical University of Denmark (DTU), $2800 \mathrm{Kgs.}$

$7 \quad$ Lyngby (Denmark)

$8 \quad{ }^{b}$ Haldor Topsøe A/S, 2800 Kgs. Lyngby (Denmark)

$9 \quad * a j @ k t . d t u . d k$ 


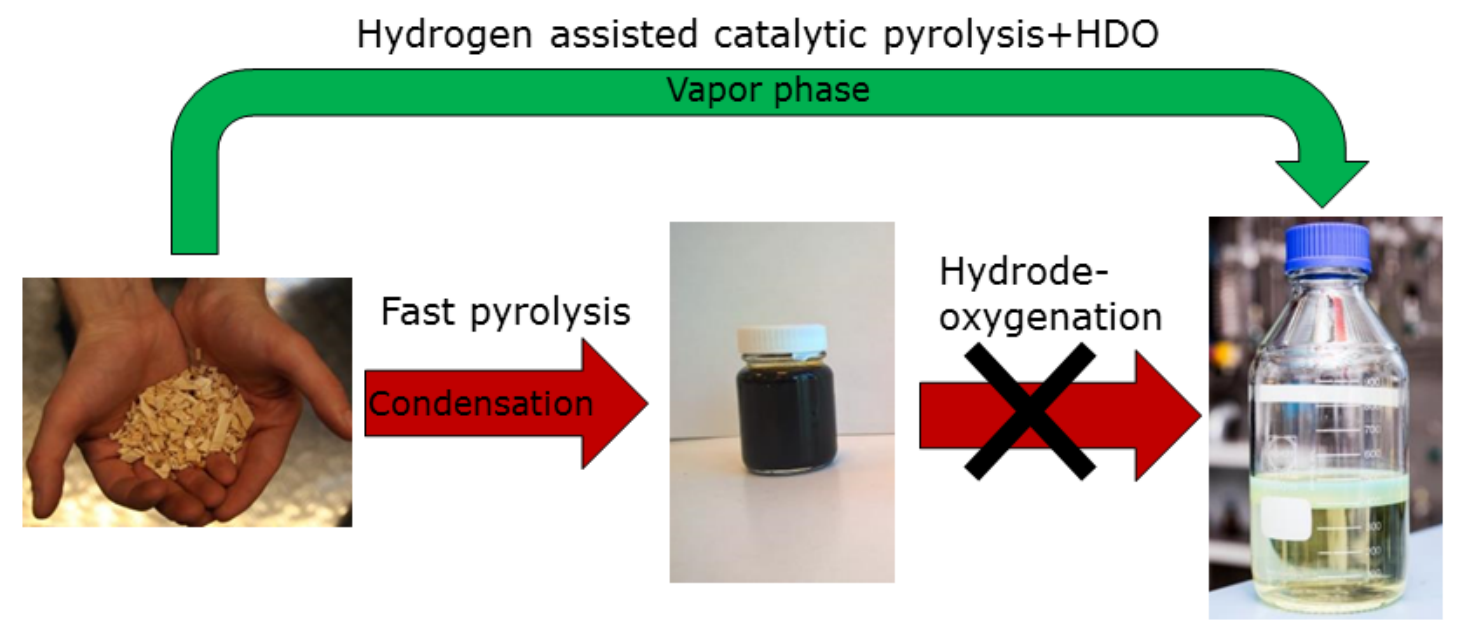

11 Highlights

- $\quad$ Catalytic hydropyrolysis of beech wood was studied at $365-511^{\circ} \mathrm{C}$ and 1.6-3.6 MPa.

- Up to $22 \%$ mass yield of condensed organics and $\mathrm{C}_{4+}$ gasses has been obtained. 


\section{Abstract}

Beech wood has been converted into a mixture of oxygen-free naphtha and diesel boiling point range hydrocarbons by using catalytic hydropyrolysis in a fluid bed reactor with a CoMoS/MgAl ${ }_{2} \mathrm{O}_{4}$ catalyst, followed by deep hydrodeoxygenation (HDO) in a fixed bed reactor loaded with a NiMoS/ $/ \mathrm{Al}_{2} \mathrm{O}_{3}$ catalyst. The effect of varying the temperature $\left(365-511^{\circ} \mathrm{C}\right)$ and hydrogen pressure (1.6-3.6 MPa) on the product yield and organic composition was studied. The mass balance closed by a mass fraction between 90 and $101 \%$ dry ash free basis (daf). The yield of the combined condensed organics and $\mathrm{C}_{4+}$ varied between a mass fraction of 17 and $22 \%$ daf, corresponding to an energy recovery of between 40 and $53 \%$ in the organic product. The yield of the non-condensable gases varied between a mass fraction of 24 and $32 \%$ daf and the char yield varied between 9.6 and $18 \%$ daf. The condensed organics contained a mass fraction of 42 to 75 \% aromatics, based on GCXGC-FID chromatographic peak area, and the remainder was primarily naphthenes with minor amounts of paraffins. The condensed organics were essentially oxygen free (mass fraction below $0.001 \%$ ) when both reactors were used. Bypassing the HDO reactor increased the oxygen concentration in the condensed liquid to a mass fraction of $1.8 \%$. The results show that catalytic hydropyrolysis may be a viable way to process solid biomass into liquid and gaseous fuels.

\section{Keywords}

\section{Catalytic hydropyrolysis}

Fluid bed

Oil characterization

Hydrodeoxygenation

Biofuel 


\section{Abbreviations}

AED Atomic emission detector

conc Concentration

daf Dry ash free basis

diAro Diaromatics

DMDS Dimethyl disulfide

FID Flame ionization detector

GC Gas chromatograph

HDO Hydrodexoygenation

HHV Higher heating value

mAro Monoaromatics

MS Mass spectrometry

Naph Naphthenes

O-Ali Oxygenated aliphatics

Par Paraffins

PhO- Oxygenated aromatics

SIMDIS Simulated distillation by GC

Temp. Temperature

tetAro+ Tetraaromatics

triAro Triaromatics 


\section{Introduction}

Recent research has shown that catalytic hydropyrolysis is an efficient process for producing diesel and gasoline hydrocarbons from biomass $[1,2]$. The reactive molecules formed by fast pyrolysis are immediately hydrogenated, thus inhibiting polymerization and other undesired properties of conventional fast pyrolysis bio-oil. In this process, the pyrolysis takes place at an elevated hydrogen pressure and in the presence of a HDO catalyst. The basic concept of hydropyrolysis share similarities with the Bergius process (high temperature and high hydrogen pressure) [3-5], however in the Bergius process coal and heavy oil is mixed into a slurry, while hydropyrolysis is a gas phase process. Steinberg et al. [6] showed in 1985 that using fast hydropyrolysis of wood at high temperatures $\left(600-1000^{\circ} \mathrm{C}\right)$ over $90 \%$ of the carbon can be converted into hydrocarbons, mainly methane and other gases. It has also been shown that catalytic hydropyrolysis of lignin can give oil mass yields up to $80 \%$ [7]. Despite that hydropyrolysis is not a new concept it has first in the recent years become a popular method for producing liquid fuels from biomass. Using a pyroprobe reactor, Melligan et al.[8] showed that conducting the pyrolysis of Miscanthus in an atmosphere of $\mathrm{H}_{2}$ instead of He decreased the concentration of ethanoic acids in bio-oil. It has also been shown that zeolites impregnated with reduced transition metals increase the hydrocarbon yield and decrease the molecular size of the phenols [8-10]. Other groups have been pursuing the high pressure, non-catalytic hydropyrolysis of biomass in an inverted cyclone or fluid bed reactors followed by downstream catalytic HDO of the product vapors prior to oil and water condensation [11-13]. Marker et al.[1,2] have proposed a process called Integrated Hydropyrolysis and Hydroconversion $\left(\mathrm{IH}^{2 \circledast}\right)$. Their process consists of a fluid bed reactor, where the catalytic hydropyrolysis takes place, and a fixed bed hydroconversion reactor, where the deep HDO takes place. Different types of biomass were tested, and the yield of condensed organic liquid and $\mathrm{C}_{4+}$ hydrocarbons in the product gas phase varied between a mass fraction of 20.6 and $46.3 \%$. The $\mathrm{IH}^{2 \circledast}$ process has been able to run continuously for $750 \mathrm{~h}$ in a pilot plant with a biomass feeding rate of $50 \mathrm{~kg}$ per day. The composition of the catalyst used in the $\mathrm{IH}^{2 \circledast}$ process has not been reported. Carbon footprint analysis of the $\mathrm{IH}^{2 \circledast}$ process showed that producing liquid fuels from this process, when compared to conventional 
production from fossil fuels, decreases the emission of greenhouse gases with 67-86 \% [14]. Dayton et al. [15-17] also conducted several studies on catalytic hydropyrolysis using loblolly pine with a setup that did not include an additional HDO reactor after the fluid bed catalytic hydropyrolysis reactor. Using a commercially available hydrotreating catalyst gave an initial low oil yield (mass fraction below $5 \%$ ), but the oil yield increased over time to a mass fraction of $12.5 \%$ as the catalyst deactivated [15]. Several experiments at different temperatures and hydrogen pressures with a commercially available NiMo hydrotreating catalyst have also been conducted with the same setup [16]. The catalyst was reduced in hydrogen and not sulfided prior to the experiments. Liquid organic yields between a mass fraction of 12.6 and $25.6 \%$ with an oxygen mass fraction between 2.4 and $11.9 \%$ and a char yield between 7.4 and $26 \%$ were obtained depending on temperature, total pressure and hydrogen partial pressure. The carbon recovery in the organic liquid and $\mathrm{C}_{4+}$ gases varied between 34.8 and $42.0 \%$, thus being significantly higher than for zeolite based catalytic pyrolysis [16]. These results indicate that catalytic hydropyrolysis is a potential technology for converting solid biomass to liquid transportation fuels. The knowledge base on this type of process in the open literature is however still scarce. Often the catalyst composition is not reported and the liquid oil produced is not characterized in depth. Furthermore the combination of catalytic hydropyrolysis followed by HDO is not fully understood.

In this study, catalytic hydropyrolysis of beech wood has been performed in a fluid bed reactor with a sulfided commercial CoMo/MgAl $\mathrm{O}_{4}$ catalyst followed by a $\mathrm{HDO}$ reactor loaded with a sulfided commercial $\mathrm{NiMo} / \mathrm{Al}_{2} \mathrm{O}_{3}$ catalyst. The concept is thus similar to the $\mathrm{IH}^{2 \circledast}$ process [1]. With this reactor combination it is expected that the biomass can be converted into a mixture of naphtha and diesel. It is well-known that the temperature is an important parameter in pyrolysis [18], thus the effect of the temperature is investigated in the range relevant for catalytic hydropyrolysis ( 365 to $511{ }^{\circ} \mathrm{C}$ ). There is also a lack of knowledge of the effect of hydrogen pressure on catalytic hydropyrolysis of wood, and the effect of pressure is therefore investigated in the range 1.6 to $3.6 \mathrm{MPa}$. Furthermore equilibrium calculations indicate that the liquid product composition changes in the tested temperature and pressure range. This is to our knowledge the 

extensively characterized.

\section{6 \\ 2 Material and methods}

\subsection{Biomass feedstock}

\subsection{Catalysts}

first study in the open literature of hydropyrolysis of wood using a sulfided hydrotreating catalyst. In order to get a comprehensive understanding of the effect of the temperature and pressure the produced oil is

Bark free beech wood supplied by Dansk Træmel (Product number: 10000251250390) was used as biomass. The particle size was approximately $200-700 \mu \mathrm{m}$. The moisture mass fraction was $6.72 \%$ (dried at $105{ }^{\circ} \mathrm{C}$ ) and the ash mass fraction was $0.59 \%$ dry basis. The composition and the higher heating value (HHV) of the beech wood are shown in Table 1.

Table 1. Composition of bark free beech wood

\begin{tabular}{lcl}
\hline $\mathrm{C}$ & 499 & $\mathrm{~g} \mathrm{~kg}^{-1}$ dry \\
$\mathrm{H}$ & 60 & $\mathrm{~g} \mathrm{~kg}^{-1} \mathrm{dry}$ \\
$\mathrm{N}$ & 1.3 & $\mathrm{~g} \mathrm{~kg}^{-1} \mathrm{dry}$ \\
$\mathrm{O}$ & 430 & $\mathrm{~g} \mathrm{~kg}^{-1}$ dry \\
$\mathrm{K}$ & 1.2 & $\mathrm{~g} \mathrm{~kg}^{-1}$ dry \\
$\mathrm{Ca}$ & 1.3 & $\mathrm{~g} \mathrm{~kg}^{-1} \mathrm{dry}$ \\
$\mathrm{S}$ & 48 & $\mathrm{mg} \mathrm{kg}^{-1}$ dry \\
$\mathrm{Na}$ & 9.9 & $\mathrm{mg} \mathrm{kg}^{-1}$ dry \\
$\mathrm{Mg}$ & 350 & $\mathrm{mg} \mathrm{kg}^{-1}$ dry \\
$\mathrm{Si}$ & 140 & $\mathrm{mg} \mathrm{kg}^{-1}$ dry \\
$\mathrm{P}$ & 75 & $\mathrm{mg} \mathrm{kg}^{-1}$ dry \\
$\mathrm{Cl}$ & 2.0 & $\mathrm{mg} \mathrm{kg}^{-1}$ dry \\
$\mathrm{Mn}$ & 170 & $\mathrm{mg} \mathrm{kg}^{-1}$ dry \\
$\mathrm{Fe}$ & 24 & $\mathrm{mg} \mathrm{kg}^{-1}$ dry \\
$\mathrm{Cu}$ & 2.1 & $\mathrm{mg} \mathrm{kg}^{-1}$ dry \\
$\mathrm{Zn}$ & 4.9 & $\mathrm{mg} \mathrm{kg}^{-1}$ dry \\
$\mathrm{Sr}$ & 4.6 & $\mathrm{mg} \mathrm{kg}^{-1}$ dry \\
$\mathrm{HHV}$ & 19.7 & $\mathrm{MJ} \mathrm{kg}^{-1}$
\end{tabular}

${ }^{*}$ Calculated from Milne formula: $0.341 \times C+1.322 \times \mathrm{H}-0.12 * 0-0.12 \times N+0.0686 * \mathrm{~S}-0.0153 \times a s h[19]$

The catalyst used in the fluid bed reactor was a CoMo/MgAl $\mathrm{O}_{4}$ catalyst supplied by Haldor Topsøe $\mathrm{A} / \mathrm{S}$. The active CoMo phase was chosen because it is an efficient hydrodeoxygenation catalyst [20-27], and $\mathrm{MgAl}_{2} \mathrm{O}_{4}$ 
was chosen as support due to its mechanical strength and moderate acidity, anticipating it would lead to less attrition and char formation in the fluidized bed. The catalyst was received as extrudates and was crushed and sieved to obtain a particle size between 180-355 $\mu \mathrm{m}$. This particle size distribution was chosen to obtain a good fluidization of the bed. A fresh load of $50 \mathrm{~g}$ catalyst was used in each experiment. The fixed bed reactor was loaded with $173 \mathrm{~g} \mathrm{NiMo/Al}{ }_{2} \mathrm{O}_{3}$ catalyst supplied by Haldor Topsøe $A / S$. The catalyst was shaped as extrudates and was used as received. To ensure a high degree of deoxygenation in all experiments the catalyst in the fixed bed reactor was replaced between experiment 5 and 6 . The catalysts in both reactors were sulfided prior to each experiment to obtain the most active phase.

\subsection{Experimental setup}

116 A bench scale setup was constructed and a simplified piping and instruction (PI) diagram is shown in Figure

117 1. The feeding system consists of a gas mixing system $\left(\mathrm{H}_{2}, \mathrm{H}_{2} \mathrm{~S}, \mathrm{~N}_{2}\right)$, where the gas flows are controlled by 118 Brooks mass flow controllers (Model: SLA5850). A liquid feeding system supplying dimethyl disulfide 119 (DMDS; Sigma-Aldrich $\geq 99 \%$ ) with a pump and evaporator (operating temperature: $200{ }^{\circ} \mathrm{C}$ ) was used for 120 sulfidation of the catalysts. Because of the relatively high cost of bottled $\mathrm{H}_{2} \mathrm{~S}$, DMDS was used during the 121 sulfidation. A pressurized vessel with a volume of $4 \mathrm{~L}$ was used for biomass feeding. A screw placed at the bottom of the vessel was used to push the biomass to the feeding tube, where it was rapidly transported by

123 a flow of hydrogen to the reactor. The biomass was preheated before entering the fluid bed reactor by

124 heating the feeding tube to approximately $200{ }^{\circ} \mathrm{C}$. To ensure a steady biomass feeding rate the biomass in 125 the vessel was continually stirred by an impeller. 


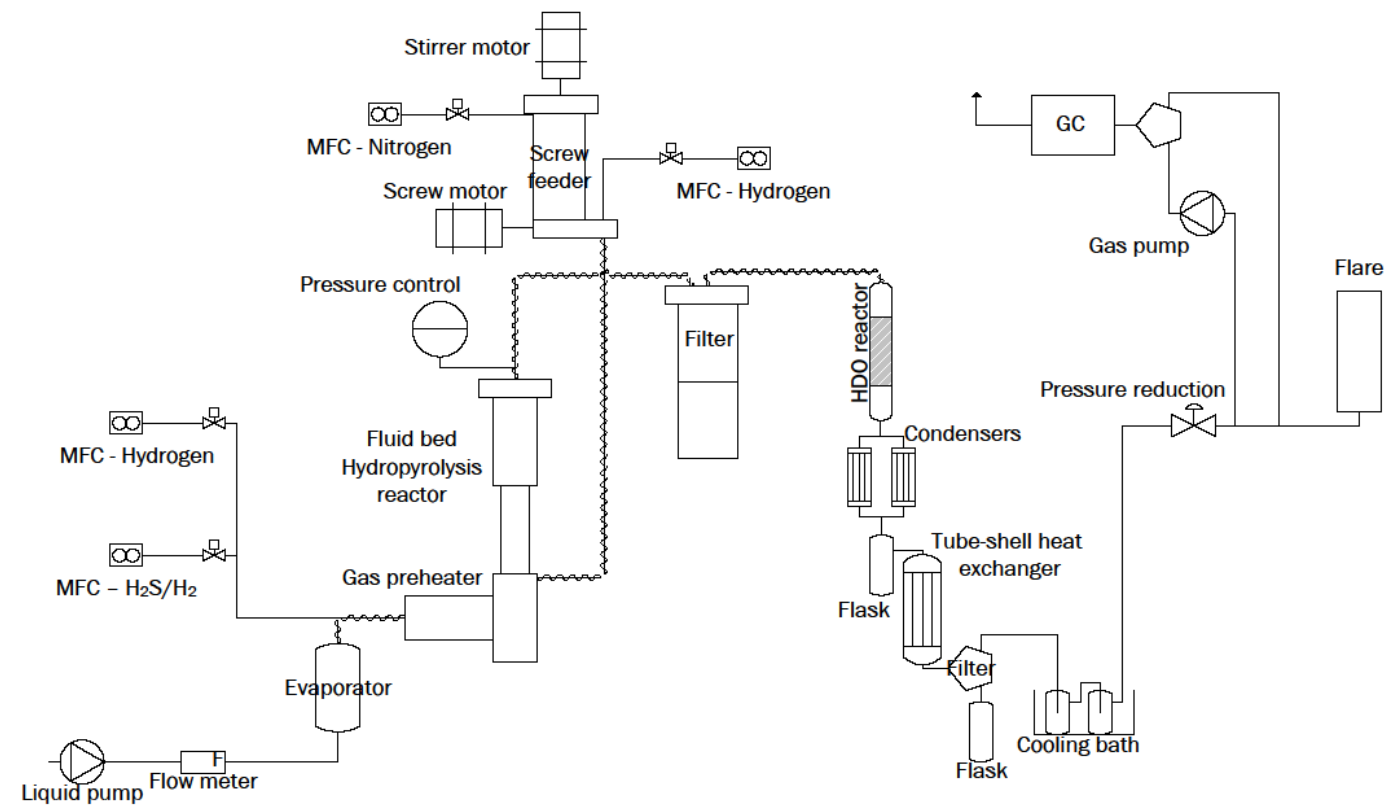

Figure 1. Simplified piping and instrumentation diagram of the used setup

128 The reactor system consisted of a fluid bed hydropyrolysis reactor, a filter, and a fixed bed 129 hydrodeoxygenation (HDO) reactor. The basic principle of the used setup is similar to the $I \mathrm{H}^{2 \otimes}$ process [1]. 130 The fluid bed reactor was made of Incoloy $800 \mathrm{HT}$ and the HDO reactor and filter were made of 316L 131 stainless steel. The fluid bed consisted of an electrical gas preheater, a gas distribution tube, a reaction 132 zone, and a disengagement zone. In order to ensure that the gas was well distributed a sintered metal plate 133 (GKN Sinter Metals SIKA-IL 10 IS, $5 \mathrm{~mm}$ height) was placed between the gas distribution tube and the 134 reaction zone. The reaction zone consisted of a $200 \mathrm{~mm}$ long tube with an inner diameter of $29.46 \mathrm{~mm}$. The 135 disengagement zone was a $200 \mathrm{~mm}$ long tube with an inner diameter of $49.25 \mathrm{~mm}$. The products exited 136 through a tube (inner diameter: $3.87 \mathrm{~mm}$ ) located $3.6 \mathrm{~cm}$ from the start of the disengagement zone, 137 however this distance was increased to $8.6 \mathrm{~cm}$ after experiment 1 . The reactor is designed in such a way that the char will be entrained out of the disengagement zone while the catalyst primarily will stay in the 
reaction zone. A multipoint thermocouple measured the temperature every $80 \mathrm{~mm}$ in the reaction zone.

The entrained solids (char and catalyst fines) were captured with a heated $\left(350{ }^{\circ} \mathrm{C}\right)$ filter. The vapors and gas were further upgraded in a fixed bed HDO reactor. This reactor consisted of a tube and a flange with a total length of $642 \mathrm{~mm}$ and an inner diameter of $32.46 \mathrm{~mm}$. The top part $(200 \mathrm{~mm})$ of the reactor was filled with glass beads and the next $360 \mathrm{~mm}$ of the reactor was loaded with the $\mathrm{NiMo} / \mathrm{Al}_{2} \mathrm{O}_{3}$ catalyst. In order to keep the catalyst in position, $20 \mathrm{~mm}$ of quartz wool and a $60 \mathrm{~mm}$ holder were placed below the catalyst bed. A multipoint thermocouple (4 points) measured the temperature through the catalyst bed. In order to avoid condensation of the vapors the tubing between the fluid bed, filter, and HDO reactor were heat traced to approximately $350^{\circ} \mathrm{C}$.

The liquid product was collected in a cooling section with 3 stage cooling $\left(20^{\circ} \mathrm{C}, 2^{\circ} \mathrm{C}\right.$, and $\left.-40{ }^{\circ} \mathrm{C}\right)$. The pressure was controlled with a backpressure regulator, and the remaining gas was sent to a flare. A small fraction of the gas was pumped through a filter to an online gas chromatograph (GC) with a flame ionization detector (FID) and two thermal conductivity detectors (TCD), which measured the gas composition ( $\mathrm{H}_{2}, \mathrm{H}_{2} \mathrm{~S}, \mathrm{~N}_{2}, \mathrm{CO}, \mathrm{CO}_{2}, \mathrm{C}_{1}$ to $\mathrm{C}_{5}$, and $\mathrm{C}_{6+}$ hydrocarbons) every 10 minutes. The total mass of the collected liquid products was determined. The amount of aqueous phase was determined by measuring the volume in a $500 \mathrm{~cm}^{3}$ graduated cylinder and assuming the density was $996.5 \mathrm{~kg} \mathrm{~m}^{-3}$, corresponding to the density of water at $25{ }^{\circ} \mathrm{C}$ and atmospheric pressure. GC-MS of the aqueous phase showed that it was essentially pure water. The amount of organic phase was then determined by subtracting the mass of the aqueous phase from the mass of the condensed liquids. The aqueous phase was separated from the organic phase using a separation funnel. The $\mathrm{H}_{2} \mathrm{~S}$ dissolved in the organic phase was removed by bubbling with $\mathrm{N}_{2}$ for approximately one hour, which lead to a mass loss between 2 and $7 \%$, mostly due to vaporization of light hydrocarbons.

After each experiment, the catalyst and remaining char was removed from the fluid bed, and replaced by a fresh batch of catalyst to be used in the subsequent experiment. The catalyst was initially sulfided at 2.6 
$\mathrm{MPa}, 350{ }^{\circ} \mathrm{C}$ with 2-7.5 mole $\% \mathrm{H}_{2} \mathrm{~S}, 5$ mole $\% \mathrm{~N}_{2}$ in 87.5-93 mole $\% \mathrm{H}_{2}$ by feeding DMDS (flow: 0.710-2.770 $\mathrm{cm}^{3} \mathrm{~min}^{-1}$ ) to the system. After sulfidation, the system was depressurized and the unconverted DMDS was collected. Then the reaction conditions listed in Table 2 were established. When the temperature in the reactors reached steady state, the experiment was started by turning on the screw feeder. The total gas inlet flow at the reaction temperature and pressure corresponded to approximately three times the minimum fluidization velocity for the used catalyst particles.

\subsection{Analysis methods}

\subsubsection{Liquid products}

Several different methods were used to analyze the condensed organic phase. The hydrogen content was measured with $\mathrm{H}-\mathrm{NMR}$ on a Bruker minispec mq20. The samples were preheated to $50{ }^{\circ} \mathrm{C}$ for 25 minutes and then moved to the measuring cell, also heated to $50^{\circ} \mathrm{C}$. The procedure followed the ASTM method D7171. The sulfur content was measured by energy dispersive X-ray fluorescence using an X-Supreme8000 instrument from Oxford Instruments, according to ASTM D4294. The simulated distillation (SIMDIS) curves were measured on two different GC's: Agilent 7890 A and Agilent 6890N. The ASTM D86 distillation curve was then calculated according to ASTM D 7213 C.

The condensed organic liquid samples were characterized by GCXGC-ToF/MS or -FID using a LECO ${ }^{\circledR}$ Pegasus $4 D^{T M}$ instrument. The instrument included an Agilent 7890A GC equipped with a Gerstel ${ }^{\circledR}$ CIS 4 PTV inlet, a secondary oven, a quad-jet, dual-stage cryogenic-based (liquid $\mathrm{N}_{2}$ ) modulator, a time-of-flight (ToF) mass spectrometer (MS) and a flame ionization detector (FID). The primary (1D) and secondary (2D) columns were Restek ${ }^{\circledR}$ Rxi-5Sil MS and Restek $^{\circledR}$ Rxi-17Sil MS, respectively.

$0.3 \mathrm{~mm}^{3}$ sample was injected in pulsed split mode (split ratio 1:50) into the PVT inlet at $40^{\circ} \mathrm{C}$, and then raised to $300^{\circ} \mathrm{C}\left(10 \mathrm{~K} \mathrm{~s}^{-1}\right)$, with a total hold up time of $1.5 \mathrm{~min}$. The main oven with the $1 \mathrm{D}$ column was held at $40^{\circ} \mathrm{C}$ for $1.5 \mathrm{~min}$ and then ramped to $290^{\circ} \mathrm{C}$ at $2.5 \mathrm{~K} \mathrm{~min}^{-1}$; the secondary oven and modulator were run 
with offsets to the main oven of $+5^{\circ} \mathrm{C}$ and $+20^{\circ} \mathrm{C}$, respectively; total run time was 101.5 min. Helium (He) was used as carrier gas at constant flow rate of $1.5 \mathrm{~cm}^{3} \mathrm{~min}^{-1}$, and the modulation period was $9 \mathrm{sec}$. For selected samples, compounds in the condensed organic phase were identified using the ToF/MS detector. The transfer line and ion source were operated at constant temperatures of $250^{\circ} \mathrm{C}$ and $225^{\circ} \mathrm{C}$, respectively. The ToF/MS was run in El mode at $70 \mathrm{eV}$ and an acquisition rate of 100 spectra sec $^{-1}$ for $\mathrm{m} \mathrm{z}^{-1}=41$ to 441 . The NIST2008 mass spectral database was used as reference. For group quantification, the FID was used. The detector was operated at $300^{\circ} \mathrm{C}$ and with a sampling rate of $100 \mathrm{~Hz}$. Based on the GCxGC-ToF/MS analysis the compounds were classified into six groups: paraffins, naphthenes, mono-, di- and tri- and higher aromatics, phenolics, and in some samples oxygenated aliphatics. The relative amount (FID area-\%) of each compound class was estimated as the sum of areas of all detected peaks in that class divided by the total peak area of all compound classes. All data was processed using the ChromaTof ${ }^{\circledR} 4.50$ software. $^{\circ}$

Selective analysis of oxygenates was conducted using a GC with an atomic emission detector (AED). An Agilent 7890A GC was coupled to a JAS 2370 AED in oxygen selective mode. The oxygen emission line at $171 \mathrm{~nm}$ was used in combination with reaction gases of $10 \%$ methane in nitrogen and pure hydrogen and with a makeup helium gas flow of $80 \mathrm{ml} \mathrm{min}^{-1}$. Cavity and transfer line were heated to $320^{\circ} \mathrm{C}$. The GC column was a Phenomenex ZB-50 $(60 \mathrm{~m} \times 0.25 \mathrm{~mm} \times 0.25 \mu \mathrm{m})$ in connection with a JAS PTV inlet in split mode (1:5) and $0.5 \mathrm{~mm}^{3}$ injection. The oven was held at $40^{\circ} \mathrm{C}$ for $1 \mathrm{~min}$ and then ramped to $340^{\circ} \mathrm{C} @ 7 \mathrm{~K}$ $\min ^{-1}$.

Quantification was done by adding known amounts of 4-fluorophenol (CAS number: 371-41-5) to known amounts of the sample. The signal for the internal standard was used for calibration of the other oxygenates in the sample. To increase the sensitivity of the method and to remove potential interferences from the sample matrix the polar compounds were extracted from the sample by use of Solid Phase Extraction on silica based cartridges. The weighted sample including the internal standard was transferred to the Si-SPE cartridge with n-heptane and the non-polar fraction eluted from the cartridge with 10 
absorbent volumes of $n$-heptane. The polar compounds were subsequently eluted with 3 absorbent volumes of acetone. The acetone fraction containing the polar compounds were reduced over nitrogen to about $300 \mathrm{~mm}^{3}$ and injected in the GC for oxygen selective detection. Identification of individual compounds was done after analysis of pure compounds.

Selective analysis of sulfur containing compounds was also conducted using GC-AED using the sulfur emission line at $181 \mathrm{~nm}$. The GC column was a Phenomenex ZB-1 $(30 \mathrm{~m}$ X $0.25 \mathrm{~mm}$ X $1.0 \mu \mathrm{m})$ in connection with a JAS split/splitless inlet in split mode $(1: 10)$ and $0.5 \mathrm{~mm}^{3}$ injection. The oven was held at $40^{\circ} \mathrm{C}$ for 5 min and then ramped to $340^{\circ} \mathrm{C} @ 10 \mathrm{~K} \mathrm{~min}^{-1}$ and a final time of $10 \mathrm{~min}$.

Quantification was done using an external standard sample containing known amounts of benzothiophene, dibenzothiophene and 4-methyl-dibenzothiophene. Identification of individual compounds was done after analysis of pure compounds. The samples were diluted if necessary in a suitable solvent prior to GC analysis.

The aqueous phase was analyzed on a Shimadzu GC-MS/FID with a Supelco Equity-5 column. The compounds were identified on the MS and quantified using the parallel FID. The concentration of phenol was determined by use of external standards. The concentration of the remaining hydrocarbons was determined from the FID signal using the effective carbon number method [28].

\subsubsection{Solid sample analysis}

The elemental composition (CHNS) of the biomass was analyzed on a Eurovector EA-3000 elemental analyzer and the oxygen content was determined by difference. The elemental composition (CHNSO) of the produced char was analyzed at DB Lab A/S using a Flash 2000 elemental analyzer from Thermo Fisher. The relative uncertainty for the $\mathrm{C}, \mathrm{H}, \mathrm{N}, \mathrm{O}$, and $\mathrm{S}$ on the char was $1.0,2.0,2.0,3.0,2.0 \%$, respectively. In order to obtain a more homogeneous sample the char was crushed prior to this analysis. Other elements were determined by wavelength dispersive X-ray fluorescence using a Supermini 200 XRF instrument from Rigaku. Samples were ashed and the ash fused to a bead with lithium metaborate $\left(\mathrm{BO}_{2} \mathrm{Li}\right)$ prior to analysis. 
The ash and catalyst content in the produced char was measured by combusting the samples at $600{ }^{\circ} \mathrm{C}$ in air. The ash content in char was calculated by assuming that all the ash in the biomass ends in the char and the catalyst content was calculated by difference.

\section{Results and Discussion}

\subsection{Effect of temperature and pressure on the product distribution}

The effect of operating conditions on catalytic hydropyrolysis of beech wood was studied by varying the total pressure and the temperature in the fluid bed and the HDO reactor as shown in Table 2. The temperature in the fluid bed was between 365 and $511{ }^{\circ} \mathrm{C}$ and the temperature in the HDO reactor was between 345 and $400{ }^{\circ} \mathrm{C}$. The total pressure was varied between 1.6 and $3.6 \mathrm{MPa}$. In experiments 1 to 8 the $\mathrm{H}_{2} \mathrm{~S}$ concentration was $460 \times 10^{-6}$ mole fraction, while it was approximately $50 \times 10^{-6}$ mole fraction in experiments 9 to 11 . Due to the short experimental time (1.2-4 hours) the catalysts have most likely remained sulfided during the experiments with low $\mathrm{H}_{2} \mathrm{~S}$ concentration. The obtained mass balances varied between 90 and $101 \%$ daf on the basis of the used biomass. In experiment 6 the entrance to the fluid bed plugged, thus stopping the experiment after only 1.2 hours, which is the reason for the poor mass balance of 90 daf. The short operation time of experiment 6 is part of the reason for the low obtained yields, with exception of the char yield. The organic yield (mass fraction daf basis) including condensed organics and $\mathrm{C}_{4+}$ gases varied between 16.6 to $22.5 \%$ daf, the $\mathrm{C}_{1}-\mathrm{C}_{3}$ gas yield varied between 10.6 to $15.5 \%$, the $\mathrm{CO}_{+}+\mathrm{CO}_{2}$ yield varied between 13.2 to $17.5 \%$, the char yield varied between 9.56 to $18.5 \%$, and the aqueous yield varied between 31.2 to $37.8 \%$. The carbon recovery for the condensed organics and $\mathrm{C}_{4+}$ gases varied between 28.0 and $38.4 \%$, and for the $C_{1}-C_{3}$ gases the carbon recovery was 19.0-24.3\%. An overview of hydrogen and oxygen recovery compared to the biomass input is shown in Table S.1. The yields of condensed organics and $\mathrm{C}_{4+}$ are lower than what has been reported for the $\mathrm{IH}^{2 \circledast}$ process, where the yield was between a mass fraction of 26 and $30 \%$ daf, when using wood [1,2]. The reason for this difference may 
257 be due to a different biomass or the use of a different catalyst. The repeatability was tested in experiment 2584 and 5, where the process conditions were similar. The product distribution in experiment 5 was quite 259 similar to experiment 4 with yields deviating less than a mass fraction of $1 \%$ points, indicating that 260 experiments were reproducible. Depending on the applied test conditions between 2.6 and $33 \%$ of the 261 catalyst loaded in the fluid bed was transported to the filter during the experiments. The biomass feeding 262 rate was difficult to control and varied between 161 and $300 \mathrm{~g} \mathrm{~h}^{-1}$. However, due to the large excess of 263 hydrogen it is expected that the feeding rate and weight hourly space velocity ( $\mathrm{g}$ biomass ( $\mathrm{g}$ catalyst $\mathrm{hr})^{-1}$ ) 264 did not have an impact on the results, and this is also supported by the experimental results. 
Table 2. Summary of reaction conditions and mass balances for catalytic hydropyrolysis of beech wood

\begin{tabular}{|c|c|c|c|c|c|c|c|c|c|c|c|}
\hline Test: & 1 & 2 & 3 & 4 & 5 & 6 & 7 & 8 & 9 & 10 & 11 \\
\hline \multicolumn{12}{|l|}{ Test conditions } \\
\hline \multicolumn{12}{|l|}{ T. $\left({ }^{\circ} \mathrm{C}\right)$} \\
\hline HDO T. $\left({ }^{\circ} \mathrm{C}\right)$ & 370 & 345 & 400 & 390 & 394 & 395 & 371 & 363 & 370 & 364 & - \\
\hline Pressure (MPa) & 2.6 & 2.6 & 2.6 & 2.6 & 2.6 & 2.6 & 2.6 & 2.6 & 1.6 & 3.6 & 2.6 \\
\hline Feed time (h) & 3.5 & 2.6 & 4.0 & 4 & 3.6 & 1.2 & 4.0 & 3.0 & 4.0 & 4.0 & 3.9 \\
\hline Feeding rate $\left(\mathrm{g} \mathrm{h}^{-1}\right)$ & 282 & 194 & 212 & 233 & 300 & 239 & 250 & 171 & 161 & 159 & 174 \\
\hline $\begin{array}{l}\mathrm{H}_{2} \mathrm{~S} \text { (mole frac. } \times \\
10^{6} \text { ) }\end{array}$ & 460 & 460 & 460 & 460 & 460 & 460 & 460 & 460 & 47 & 50 & 48 \\
\hline \multicolumn{8}{|l|}{ 1) } & 3.35 & 2.14 & 5.08 & 3.57 \\
\hline \multicolumn{12}{|l|}{$\left.{ }^{1}\right)$} \\
\hline \multicolumn{11}{|l|}{$\overline{\text { Biomass used }(\mathrm{kg})}$} & 35 \\
\hline \multicolumn{12}{|c|}{ Yields (mass fraction \% daf) } \\
\hline Gas & 30.0 & 25.8 & 28.8 & 32.3 & 31.3 & 23.9 & 31.5 & 32.2 & 30.3 & 26.3 & 27.4 \\
\hline Char & 14.2 & 14.6 & 15.0 & 11.4 & 11.9 & 18.5 & 11.4 & 9.56 & 11.0 & 12.7 & 12.2 \\
\hline Aqueous phase & 35.7 & 37.8 & 35.9 & 36.1 & 36.0 & 31.2 & 35.2 & 35.6 & 33.2 & 37.7 & 37.0 \\
\hline Organics & 11.6 & 8.8 & 9.9 & 11.4 & 12.7 & 7.9 & 12.4 & 11.1 & 11.0 & 10.6 & 12.0 \\
\hline $\mathrm{C}_{4+}$ in the gas & 8.6 & 10.1 & 11.5 & 10.3 & 8.7 & 8.8 & 9.1 & 11.3 & 8.7 & 10.3 & 8.4 \\
\hline Organics $+\mathrm{C}_{4+}$ & 20.2 & 18.9 & 21.4 & 21.7 & 21.4 & 16.7 & 21.5 & 22.4 & 19.7 & 20.9 & 20.4 \\
\hline Mass balance & 100.1 & 97.1 & 101.1 & 101.5 & 100.6 & 90.3 & 99.6 & 99.8 & 94.2 & 97.6 & 97.0 \\
\hline \multicolumn{12}{|l|}{ Carbon recovery (\%) } \\
\hline $\mathrm{C}_{1}-\mathrm{C}_{3}$ & 21.5 & 19.7 & 23.1 & 22.9 & 21.6 & 19.4 & 22.5 & 24.3 & 18.9 & 20.7 & 19.0 \\
\hline $\mathrm{C}_{4+}$ & 14.2 & 16.8 & 18.9 & 16.9 & 14.5 & 14.4 & 15.1 & 18.8 & 14.4 & 17.1 & 13.9 \\
\hline $\mathrm{CO}+\mathrm{CO}_{2}$ & 11.4 & 9.3 & 10.1 & 12.7 & 12.5 & 8.2 & 12.1 & 12.7 & 13.3 & 10.3 & 12.6 \\
\hline Char & 20.9 & 21.0 & 22.0 & 17.3 & 18.2 & 26.4 & 17.2 & 15.5 & 15.5 & 18.9 & 18.4 \\
\hline Organics & 19.9 & 15.1 & 17.2 & 20.3 & 22.6 & 13.6 & 21.4 & 19.6 & 19.4 & 18.6 & 20.9 \\
\hline Aqueous phase & 0.0 & 0.0 & 0.0 & 0.0 & 0.0 & 0.0 & 0.0 & 0.0 & 0.0 & 0.0 & 0.6 \\
\hline Sum & 87.9 & 82.0 & 91.3 & 90.1 & 89.5 & 82.0 & 88.4 & 90.9 & 81.4 & 85.5 & 85.4 \\
\hline \multicolumn{12}{|c|}{ Organic composition (mass fraction \%) } \\
\hline$C^{*}$ & 87.5 & 87.7 & 88.3 & 88.8 & 88.2 & 88.2 & 88.0 & 88.32 & 88.4 & 88.1 & 89.5 \\
\hline $\mathrm{H}$ & 12.5 & 12.3 & 11.7 & 11.2 & 11.7 & 11.8 & 11.9 & 10.89 & 11.2 & 11.6 & 10.2 \\
\hline $\mathrm{O}$ & $<0.001$ & $<0.001$ & $<0.001$ & $<0.001$ & $<0.001$ & $<0.001$ & $<0.001$ & $<0.001$ & $<0.001$ & $<0.001$ & 1.8 \\
\hline $\mathrm{S}$ & 0.0699 & 0.34 & ND & 0.113 & 0.0909 & ND & 0.117 & 0.794 & 0.417 & 0.246 & 0.302 \\
\hline \multicolumn{12}{|c|}{ Aqueous phase composition (mass fraction \%) } \\
\hline Organics & 0 & 0 & 0 & 0 & 0 & 0 & 0 & 0 & 0 & 0 & 1.15 \\
\hline \multicolumn{12}{|c|}{ Gas composition (mass fraction \% daf) } \\
\hline $\mathrm{CO}$ & 8.01 & 6.76 & 8.31 & 10.4 & 9.64 & 6.48 & 9.74 & 11.7 & 10.8 & 9.92 & 11.1 \\
\hline $\mathrm{CO}_{2}$ & 8.27 & 6.51 & 5.60 & 6.90 & 7.88 & 4.83 & 7.96 & 5.05 & 7.55 & 3.26 & 5.71 \\
\hline $\mathrm{C}_{1}-\mathrm{C}_{3}$ & 13.7 & 12.5 & 14.8 & 14.7 & 13.8 & 12.4 & 12.9 & 15.5 & 12.0 & 13.2 & 12.1 \\
\hline $\mathrm{C}_{4+}$ & 8.58 & 10.1 & 11.5 & 10.3 & 8.74 & 8,78 & 8.83 & 11.3 & 8.67 & 10.3 & 8.35 \\
\hline \multicolumn{12}{|c|}{ Char composition (mass fraction \%) } \\
\hline $\mathrm{C}$ & 71 & 69 & 73 & 72 & 68 & 67 & 72 & 76 & 67 & 70 & 72 \\
\hline $\mathrm{H}$ & 3.7 & 3.8 & 3.9 & 3.4 & 3.4 & 4.0 & 3.7 & 3.4 & 3.5 & 3.5 & 3.4 \\
\hline $\mathrm{N}$ & 0.54 & 0.54 & 0.56 & 0.45 & 0.37 & 0.45 & 0.41 & 0.39 & 0.40 & 0.40 & 0.41 \\
\hline$S$ & 0.50 & 0.55 & 0.48 & 0.66 & 0.63 & 0.49 & 0.53 & 0.77 & 1.13 & 0.62 & 0.61 \\
\hline 0 & 20 & 21 & 21 & 18 & 16 & 22 & 18 & 13 & 23 & 19 & 19 \\
\hline Ash & 4.0 & 5.0 & 4.4 & 5.6 & 5.3 & 6.5 & 5.0 & 6.5 & 4.6 & 5.5 & 4.8 \\
\hline
\end{tabular}

267 The temperature in the two reactors was varied simultaneously in experiments 1 to 8 . The results from

268 experiment 2 and 3 show that increasing the temperature in the HDO reactor increased the yield of $C_{1}-C_{3}$

269 slightly, but in general only had a minor effect on the product distribution. Varying the temperature in the

270 fluid bed reactor changed the product distribution as shown in Figure 2. Increasing the temperature in the 
271 fluid bed reactor mainly decreased the char yield, while increasing the gas yield, in agreement with the 272 general observations in the pyrolysis literature [29-32] and with the results obtained with $\mathrm{IH}^{2 \circledast}$ process [1].

273 The organic yield including condensed organics and $\mathrm{C}_{4+}$ gases increased when the fluid bed temperature 274 increased from 365 to $400{ }^{\circ} \mathrm{C}$ above which it remained constant within the experimental uncertainty. The 275 aqueous mass yield increased from 31 to $36 \%$ daf when the fluid bed temperature increased from 365 to $276400{ }^{\circ} \mathrm{C}$, while further increasing the fluid bed temperature had a negligible impact on the aqueous yield. 277 Hydrocarbons were not observed in the aqueous phase for experiments 1 to 10 where the HDO reactor was 278 used. Interestingly, Dayton et al.[16] using a reduced NiMo catalyst observed an increase in char yield from 27910.8 to 26.0 and a decreased yield of condensed organics from 25.6 to 16.8 when the temperature 280 increased from 375 to $475^{\circ} \mathrm{C}$. Their results indicate accelerated cracking over the applied catalyst at 281 elevated temperatures, which was not observed in our study. 

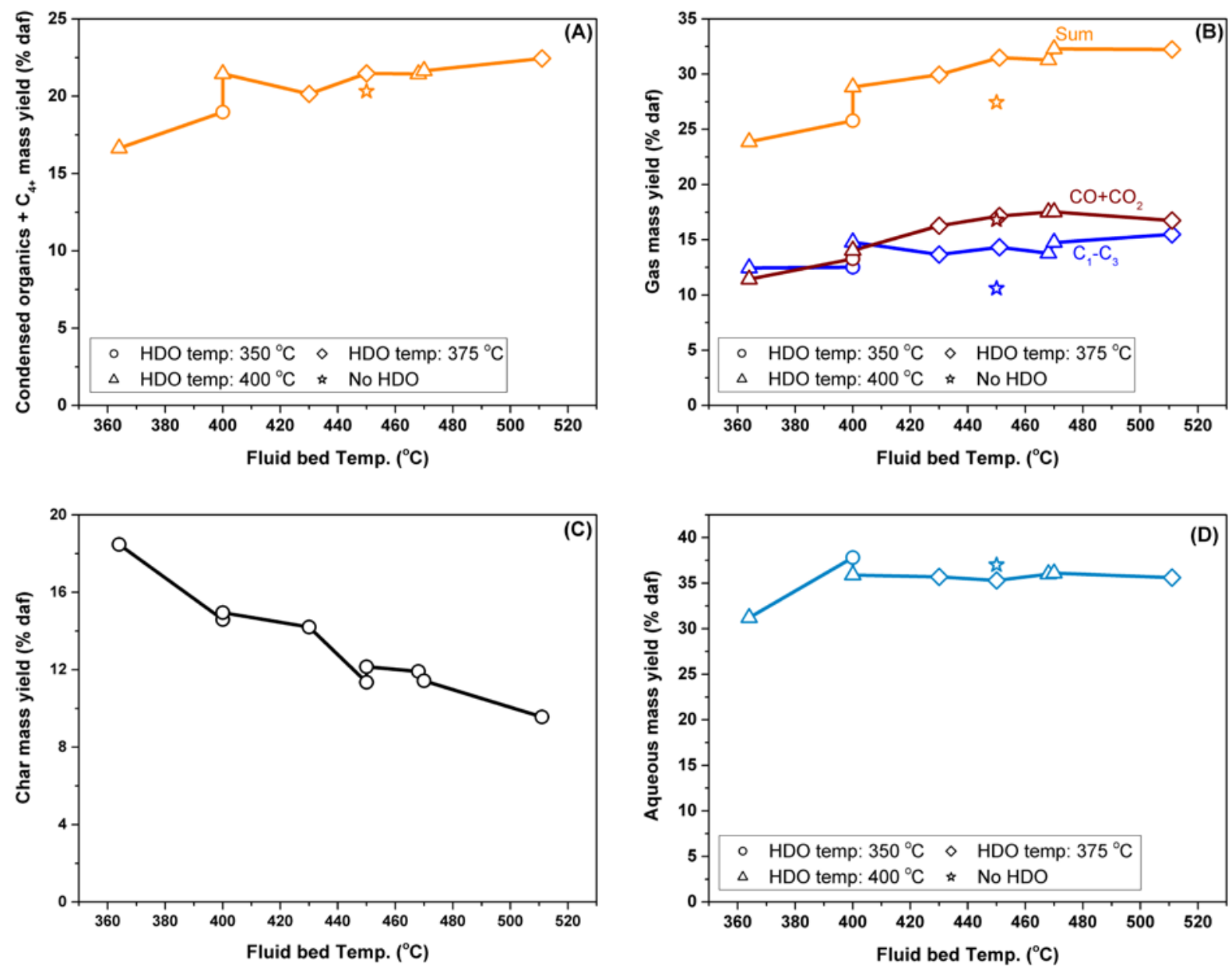

Figure 2. Effect of temperature on the yield of condensed organic liquid and $C_{4+}$ gases (A), yield of light gases (B), char yield (C), and aqueous yield (D). Conditions: pressure: $2.6 \mathrm{MPa}, \mathrm{H}_{2}$ flow: 3.27-3.35 mole $\mathrm{min}^{-1}, \mathrm{~N}_{2}$ flow: 0.20 mole min $^{-1}$, biomass feeding rate: $212-300 \mathrm{~g} \mathrm{~h}^{-1}, \mathrm{H}_{2} \mathrm{~S}$ concentration: $460 \times 10^{-6}$ mole fraction.

A small decrease in the yield of condensed organic liquid and $\mathrm{C}_{4+}$ gases and an increase in the aqueous yield was observed when the HDO reactor was bypassed as seen by comparison of experiments 7 and 11 in Table 2. GC-FID/MS of the aqueous phase from experiment 11 showed that it contained small amounts of oxygenated aliphatics and phenols, with a total organic mass fraction of $1.15 \%$ corresponding to an organic yield of a mass fraction of $0.51 \%$ daf. The dissolved oxygenates in the aqueous phase can partly explain the observed decrease in yield of condensed organics and $C_{4+}$ when comparing experiment 11 with experiment 7. The total $\mathrm{CO}$ and $\mathrm{CO}_{2}$ yield did not decrease when the $\mathrm{HDO}$ reactor was bypassed, but a decrease in the $\mathrm{C}_{1}-\mathrm{C}_{3}$ yield was observed. This indicates that the remaining oxygen is mainly removed by hydrogenation in the HDO reactor, but hydrocracking also takes place in the $\mathrm{HDO}$ reactor. However, the $\mathrm{CO}_{2}$ mass yield 
decreased from $7.96 \%$ daf in the experiment with the HDO reactor (experiment 7) to $5.71 \%$ daf when the HDO reactor was bypassed (experiment 11), while the CO yield increased from 9.71 to $11.1 \%$ daf. 297 Considering that the aqueous phase yield also increased when the HDO reactor was bypassed, this 298 indicates that the water gas shift reaction takes place in the HDO reactor. In the experiments where the 299 HDO reactor was used no olefins were detected in the gaseous products. However, when the HDO reactor 300 was bypassed, olefins accounted for $26 \%$ of the $C_{2}-C_{5}$ hydrocarbons in the gas phase. The hydrogen to 301 biomass consumption also decreased from $46 \mathrm{~g} \mathrm{~kg}^{-1}$ to $35 \mathrm{~g} \mathrm{~kg}^{-1}$ when the HDO reactor was bypassed.

302 The influence of pressure on the product distribution is shown in Figure 3, by comparison of experiment 7, 3039 , and 10 in Table 2. Increasing the total pressure did not affect the liquid organic yield, but it increased the 304 aqueous yield, while decreasing the $\mathrm{CO}$ and $\mathrm{CO}_{2}$ yield. This was most likely due to the increase in hydrogen 305 partial pressure, which makes oxygen removal by hydrodeoxygenation more favorable compared to 306 cracking. The hydrogen to biomass consumption also increased from $35 \mathrm{~g} \mathrm{~kg}^{-1}$ at $1.6 \mathrm{MPa}$ to $46 \mathrm{~g} \mathrm{~kg}^{-1}$ at 3.6 $307 \mathrm{MPa}$, but did not increase further when the pressure increased to $3.6 \mathrm{MPa}$. The char yield also increased 308 slightly with increasing pressure; however this is within the experimental uncertainty. Dayton et al.[16] 309 observed an increase in the hydrogen to biomass consumption from between 20 to $25 \mathrm{~g} \mathrm{~kg}^{-1}$ at a $\mathrm{H}_{2}$ volume 310 fraction of $20 \%$, to between 35 to $38 \mathrm{~g} \mathrm{~kg}^{-1}$ at $40 \%$ at $2.168 \mathrm{MPa}$. However, they did not observe a related 311 increase in the aqueous yield, thus indicating that hydrogenation of the olefins increased with increasing 312 hydrogen partial pressure [16]. 

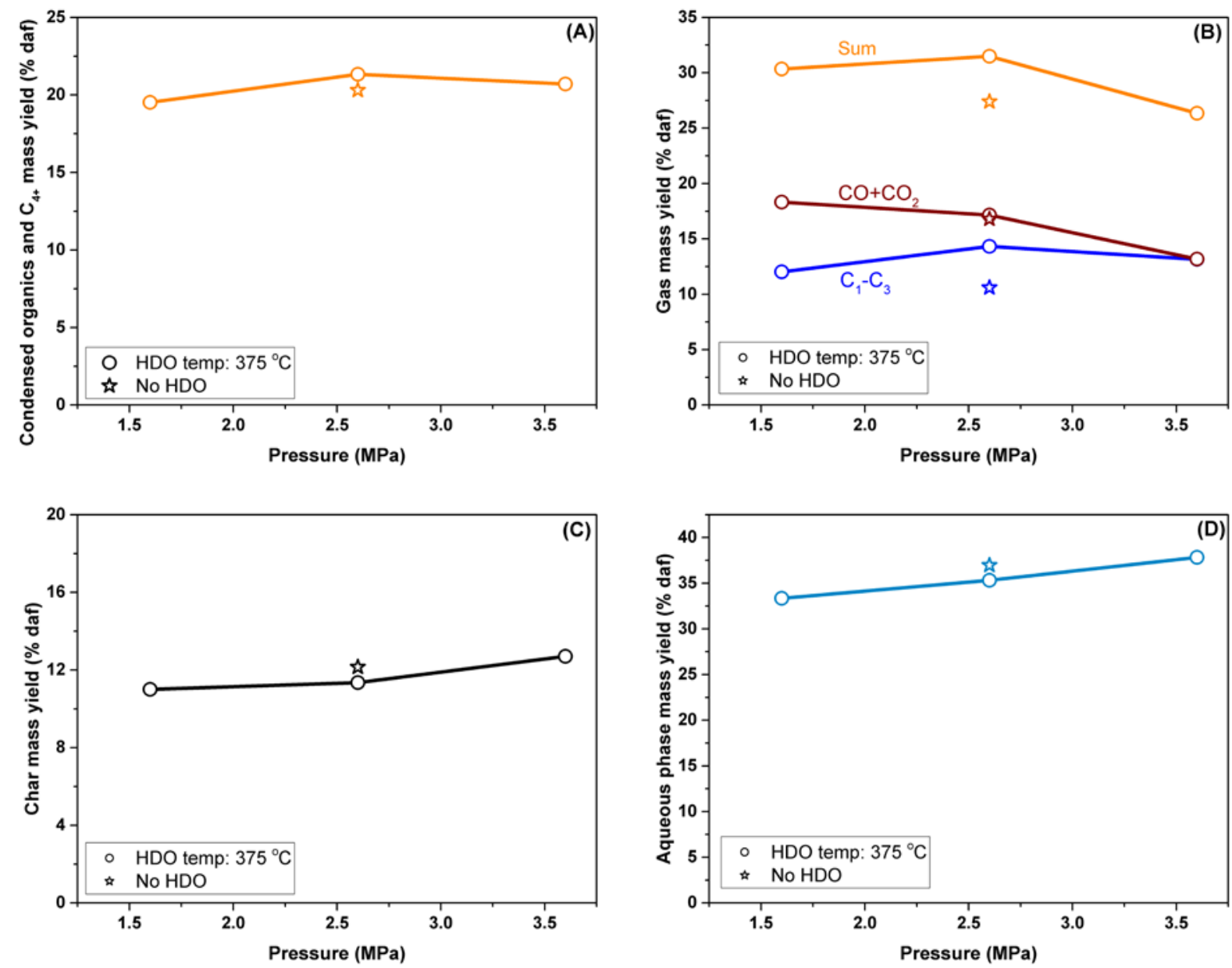

Figure 3. Effect of pressure on the organic liquid and $C_{4+}$ gases yield (A), gas yield (B), char yield (C), and aqueous liquid yield (D).

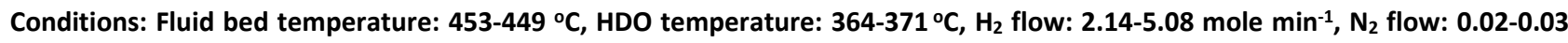
mole $\mathrm{min}^{-1}$, biomass feeding rate: $159-250 \mathrm{~g} \mathrm{~h}^{-1}, \mathrm{H}_{2} \mathrm{~S}$ concentration: $47-460 \times 10^{-6}$ mole fraction.

\subsection{Chemical composition of the condensed organics}

In the experiments where the HDO reactor was used the hydrogen mass fraction of the condensed organics was between $10.9 \%$ and $12.5 \%$. When the HDO reactor was bypassed the hydrogen mass fraction decreased to $10.2 \%$, indicating that olefins and aromatics are saturated in the HDO reactor. The simulated distillation curves for the condensed organics are shown in Figure 4. As can be seen, a volume fraction of 20 to $40 \%$ was naphtha, while the rest were in the diesel boiling point range. However, the uncondensed $\mathrm{C}_{4+}$ organics, that were detected in the gas phase, are most likely mainly naphtha, making a total naphtha mass 
curves for experiment 7 and 11 shows that the boiling point for the condensed organics increased when the

HDO reactor was bypassed (see supplementary material Figure S.1), this was due to the increased oxygen concentration in the product. For the condensed organics from experiment 8 , a volume fraction of $99.5 \%$ of the organics had a boiling point below $308{ }^{\circ} \mathrm{C}$, thus indicating that increasing the fluid bed temperature to $511{ }^{\circ} \mathrm{C}$ decreased the boiling point, possibly due to increased cracking of the vapors. Varying the pressure only had a small effect on the distillation curves (experiment: 7,9 and 10) that was within the experimental uncertainty.

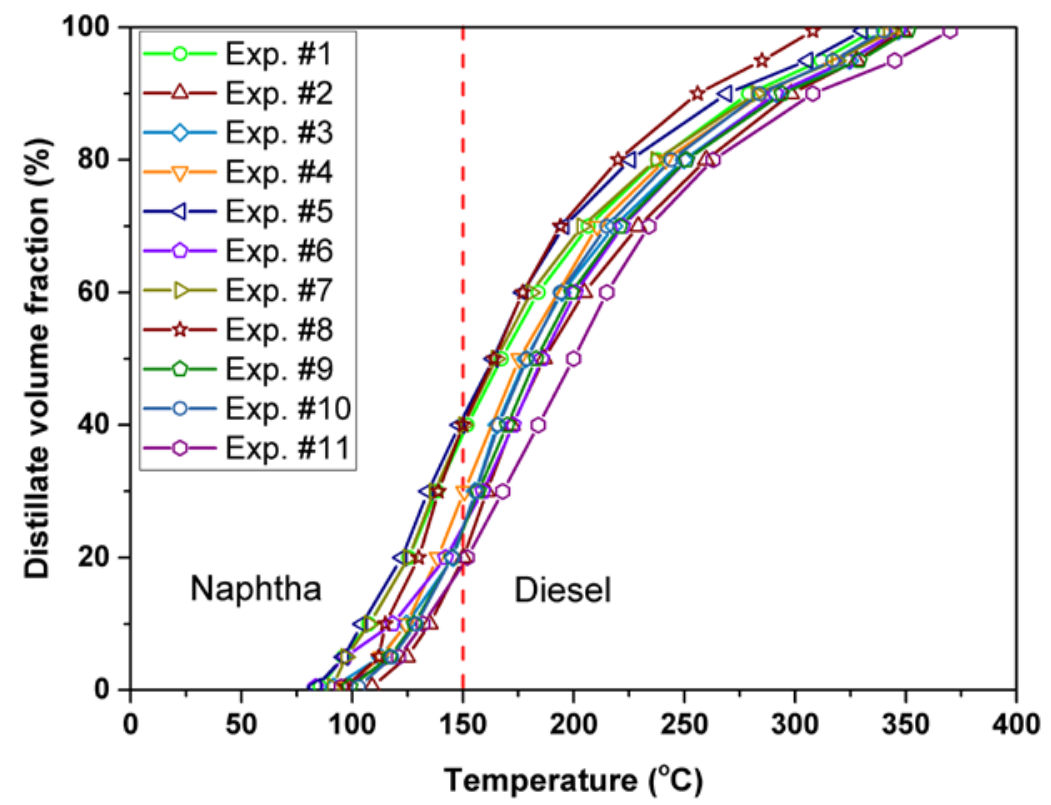

Figure 4. GC simulated distillation curves for the condensed organics. The curves are calculated using D86 according to ASTM D 7213 C.

334 GCXGC-FID and GC-AED was used to gain a deeper insight into composition of the condensed organics. GC335 AED was used to selectively identify the sulfur and oxygen containing compound classes in the condensed 336 organics. GCXGC-FID was used to measure the concentration of the different types of hydrocarbons and an example of a chromatogram is shown in Figure 5. 


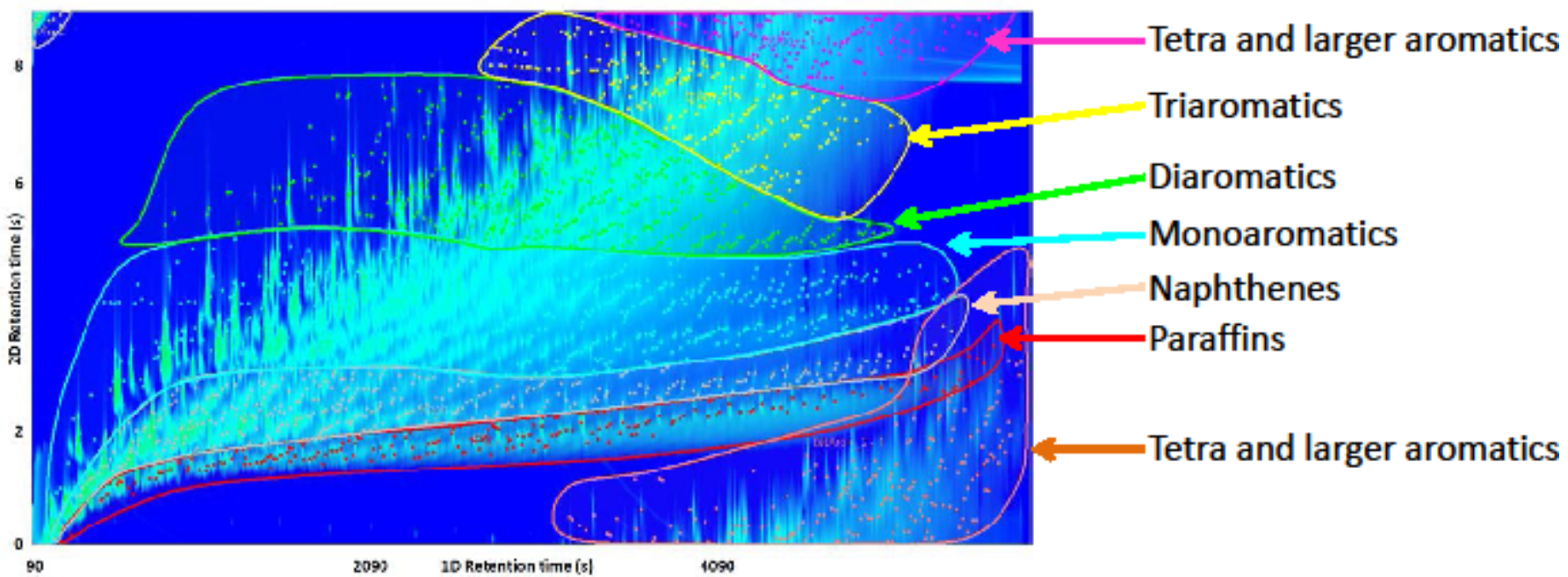

Figure 5. GCXGC-FID contour plot of the condensed organics from experiment 4. Conditions: Fluid bed mole $\min ^{-1}$, biomass feeding rate: $233 \mathrm{~g} \mathrm{~h}^{-1}, \mathrm{H}_{2} \mathrm{~S}$ concentration: $4.6 \times \mathbf{1 0}^{-6}$ mole fraction.

The concentration of paraffins was between 2.5 and $5.1 \%$ peak area. The concentration of aromatics and naphthenes are shown as a function of the fluid bed temperature and the total pressure in Figure 6. Between $35 \%$ (experiment 1) and $60 \%$ area-FID (experiment 4) of the aromatics were monoaromatics, but considerable amounts of diaromatics were also present (up to $13 \%$ ), while only low concentrations (below $4.5 \%)$ of tri- and larger aromatics were observed. The concentration of aromatics decreased when the temperature in the fluid bed was increased from 365 to $430{ }^{\circ} \mathrm{C}$, but increased when the temperature was further increased. Equilibrium calculations for monoaromatics show that they are favored over the corresponding naphthenes when the temperature is above $405{ }^{\circ} \mathrm{C}$ (see supplementary material Figure S.2 and Figure S.3). This indicates that the hydrogenation of aromatics to naphtenes was kinetically controlled below $430{ }^{\circ} \mathrm{C}$ and equilibrium controlled at higher temperatures. The HDO reactor has only a minor influence on the aromatic concentration. In experiments 2 and 3 the fluid bed temperature was $400{ }^{\circ} \mathrm{C}$, and the temperature in the HDO reactor was 345 and $400{ }^{\circ} \mathrm{C}$ respectively, but the concentration of aromatics did not change. As shown in Figure 6B, increasing the total pressure at $450{ }^{\circ} \mathrm{C}$ in the fluid bed decreased the aromatic concentration and increased the naphthenes concentration, which is most likely due to the 

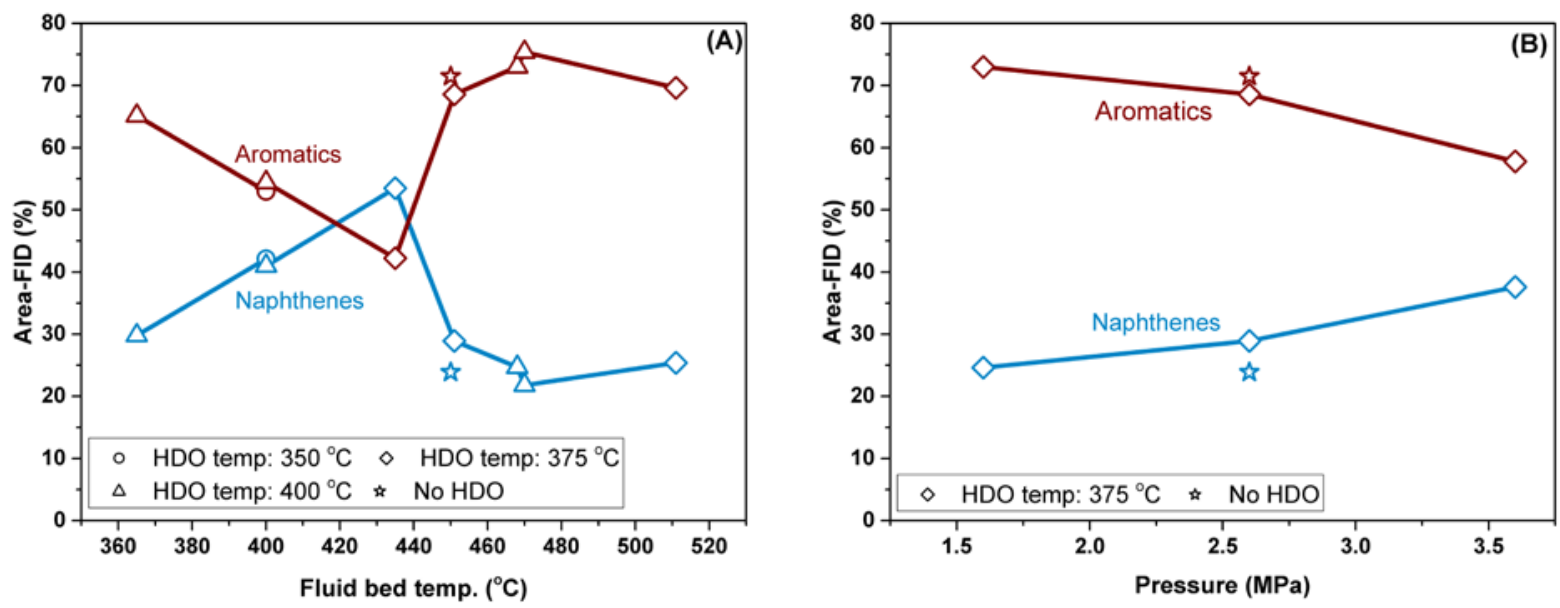

Figure 6. The effect of temperature at $2.6 \mathrm{MPa}(\mathrm{A})$ and pressure at $450^{\circ} \mathrm{C}(\mathrm{B})$ on the aromatic (including phenols) and naphthene content in the condensed organic liquid. Conditions: $\mathrm{H}_{2}$ flow: $2.14-5.08$ mole $\mathrm{min}^{-1}, \mathrm{~N}_{2}$ flow: $0.02-0.20$ mole min $^{-1}$, biomass feeding rate: $159-300 \mathrm{~g} \mathrm{~h}^{-1}, \mathrm{H}_{2} \mathrm{~S}$ concentration: $47-460 \times 10^{-6}$ mole fraction.

The result of the GCXGC-FID/MS analysis of the condensed organics in experiment 7 and 11 is shown in Figure 7. The reaction conditions in these two experiments were the same except that the HDO reactor was bypassed in experiment 11 . When the HDO reactor was bypassed (experiment 11 ) the relative area of hydrocarbons with less than 10 carbon atoms was $41 \%$ and hydrocarbons between 10 and 15 carbon atoms was $43 \%$. When the HDO reactor was used (experiment 7) the relative area for hydrocarbons with less than 10 carbon atoms increased to $53 \%$, while it decreased to $33 \%$ for hydrocarbons with between 10 and 15 carbon atoms. This decrease in carbon number mainly decreased the concentration of diaromatics. For both experiment 7 and 11 alkyl benzenes with between 15 and 20 carbon atoms were detected. In the experiment without the HDO reactor, oxygenated aliphatics and phenols were detected in the product, but they were hydrodeoxygenated in the experiment with the HDO reactor. Oxygen specific GC-AED showed that when the HDO reactor was bypassed the total oxygen mass fraction in the condensed organics was 1.8 $\%$ and that the main oxygenates were different phenols (see supplementary material Figure S.5.). When the 

and dibenzofurans were detected in the condensed organics.
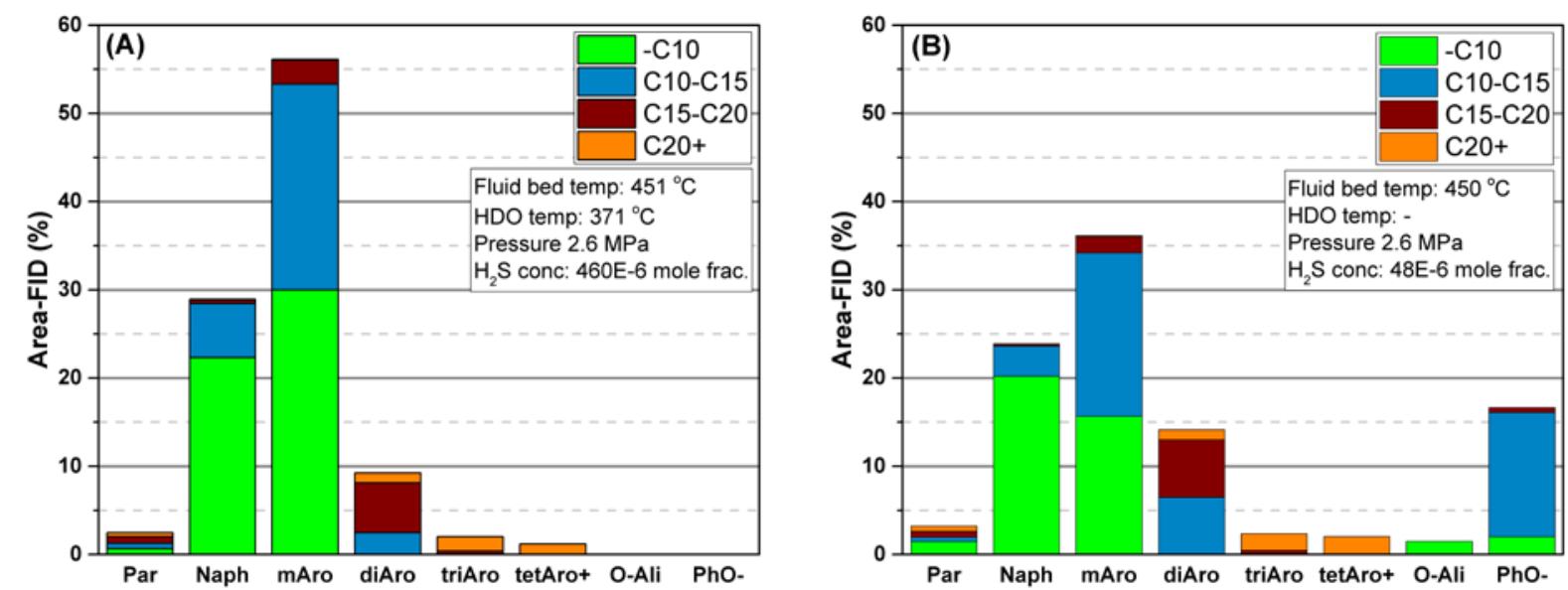

Figure 7. The composition of the condensed organic phase from experiment 7 (with HDO reactor) (A) and experiment 11 (without HDO reactor) (B). Conditions: $\mathrm{H}_{2}$ flow: 3.35-3.57 mole $\mathrm{min}^{-1}, \mathrm{~N}_{2}$ flow: $\mathbf{0 . 2 0 - 0 . 0 2}$ mole min ${ }^{-1}$, biomass feeding rate: $174-$ $250 \mathrm{~g} \mathrm{~h}^{-1}, \mathrm{H}_{2} \mathrm{~S}$ concentration: $48-460 \times 10^{-6}$ mole fraction. The components in the condensed organics is divided into paraffins (Par), naphthenes (Naph), monoaromatics (mAro), diaromatics (diAro), triaromatics (triAro), tetraaromatics and larger aromatics (tetAro+), oxygenated aliphatics (O-Ali) and oxygenated aromatics (PhO-). The components are also divided into the following groups based on the number of carbon atoms in the components: less than 10 carbons atoms (-C10) between 10 and 15 carbons atoms (C10-C15), between 15 and 20 carbon atoms (C15-C20), more than 20 carbon atoms (C20+).

The sulfur mass fraction in the condensed organics phase varied between 0.06 and $0.8 \%$, which is very high for oil produced from biomass. Therefore, the condensed organics from experiment 7 was analyzed with sulfur specific GC-AED. This showed that a large part of the sulfur was $\mathrm{H}_{2} \mathrm{~S}$, which was not properly stripped from the condensed organic phase. DMDS was also detected, thus indicating that part of the DMDS used in the sulfidation of the catalyst ended up in the condensed organics. Trimethylthiophen (S mass fraction: $0.036 \%$ ), benzothiophen (S mass fraction: $0.003 \%$ ), and a S mass fraction of $0.45 \%$ from larger unknown sulfur containing components were also detected. It is possible that part of the sulfur from the $\mathrm{H}_{2} \mathrm{~S}$ added to the gas phase is incorporated into the organics. The detected sulfur compounds are commonly encountered in petrochemical refining and can be removed by further hydrotreating - either in the online 
HDO reactor by increasing the residence time, or in a separate reactor. This would slightly increase the hydrogen consumption.

\subsection{Chemical composition of the char}

394 The carbon mass fraction in the produced char varied between 71 and $81 \%$ and increased with increasing 395 temperature in the fluid bed reactor as shown in Figure 8. The oxygen mass fraction varied between 14 and $39624 \%$ and decreased with increasing temperature in the fluid bed reactor. The carbon mass fraction 397 increased and the oxygen mass fraction decreased when the pressure increased from 1.6 to $2.6 \mathrm{MPa}$, but 398 further increasing the pressure to 3.6 MPa did not have a substantial impact on the carbon and oxygen 399 concentration. The hydrogen mass fraction decreased from $4.3 \%$ at $365^{\circ} \mathrm{C}$ to 3.7 at $511{ }^{\circ} \mathrm{C}$. The sulfur mass 400 fraction varied between 0.39 and $1.13 \%$ and the nitrogen mass fraction varied between 0.39 and $0.56 \%$.

401 Comparing the char composition in Figure 8 with the biomass composition in Table 1 shows an enrichment 402 of carbon and nitrogen in the char, which is an well-known phenomenon for pyrolysis [33]. The significant 403 sulfur enrichment in the char, indicates that part of the sulfur in the char comes from $\mathrm{H}_{2} \mathrm{~S}$ that is 404 incorporated into the char. The retention of nitrogen, carbon, oxygen and hydrogen in the char decreased 405 when the fluid bed temperature increased (see supplementary material Figure S.6). The variations in the 406 carbon content with pressure is within the experimental uncertainty.
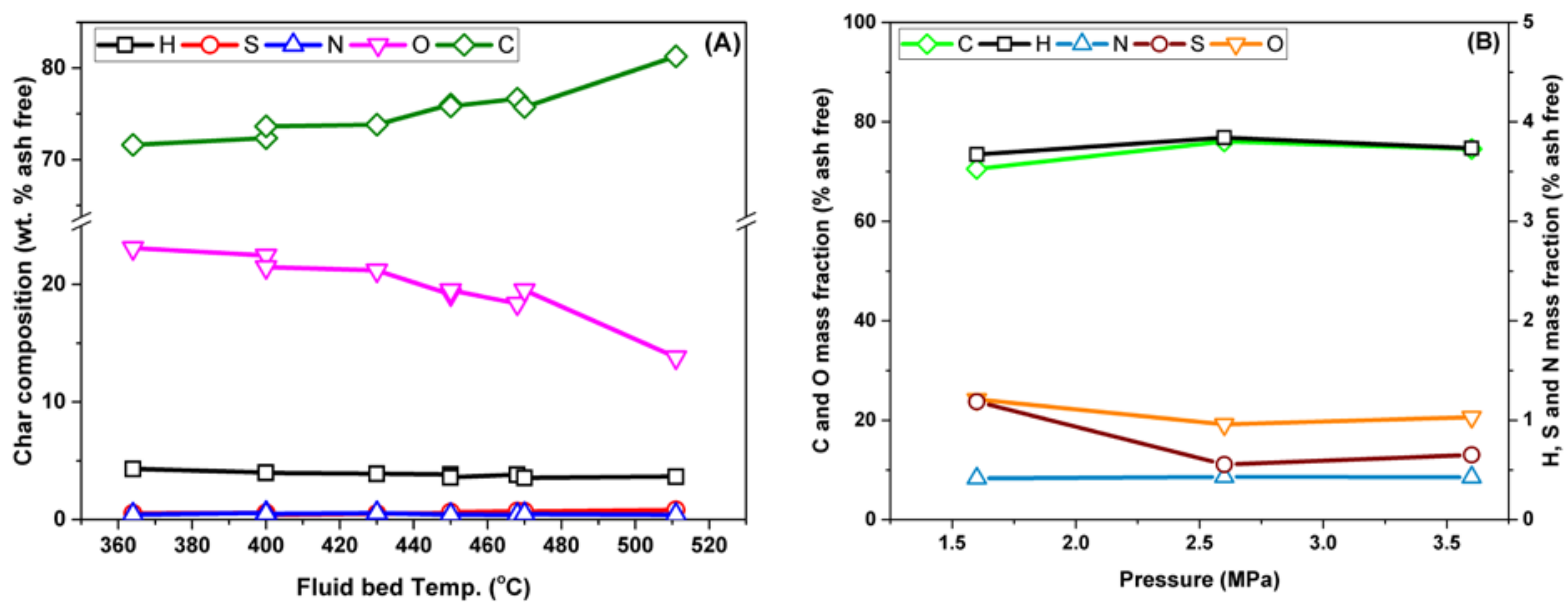
Figure 8. The effect of temperature at $2.6 \mathrm{MPa}$ (A) and pressure at $450^{\circ} \mathrm{C}$ (B) on the CHNSO composition of the char in the filter.

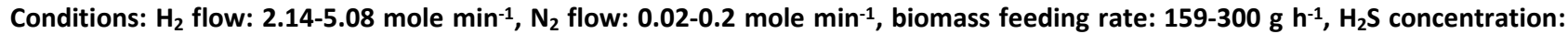
$47-460 \times 10^{-6}$ mole fraction. 
411 The energy recovery was calculated on the basis of the higher heating value (HHV) of the biomass fed to 412 the setup and the HHV of the different phases. The heating value of the char was calculated from the Milne 413 formula (see section 2.1), the heating value for the gas was calculated on the basis of the heating value of 414 the different compounds detected in the gas, and the heating value of the condensed organics was 415 calculated from their elemental (CHNSO) composition according to ref. [34]. The resulting energy recoveries for each product are shown in Figure 9. The energy recovery for the condensed organics and $\mathrm{C}_{4+}$ 417 was between 40 and $53 \%$, the energy recovery for the gas was between 36 and $45 \%$, and the energy 418 recovery for the char was between 14 and $19 \%$. The total energy recovery for all of the experiments was 419 more than $100 \%$, which is due to incorporation of hydrogen that increases the heating value of the 420 products. The energy added to the products by hydrogen corresponded to between 0.26 and $0.34 \mathrm{MJ} \mathrm{MJ}^{-1}$ 421 biomass used. The exothermic hydrogenation reactions decrease the energy recovery in the products 422 compared to the energy in the consumed biomass and hydrogen. The energy recovery for the condensed 423 organics and $\mathrm{C}_{4+}$ was directly proportional to the yield indicating that the oil quality was rather constant. At $4241.6 \mathrm{MPa}$ the energy recovery was $46 \%$, while it was 51 and $50 \%$ at 2.6 and $3.6 \mathrm{MPa}$, respectively. This is 425 because the condensed organics and $\mathrm{C}_{4+}$ yield and hydrogen content were slightly lower at $1.6 \mathrm{MPa}$ 426 compared to 2.6 and 3.6 MPa. Thus the differences in the energy recovery at the different pressures are 427 not statistically significant. 


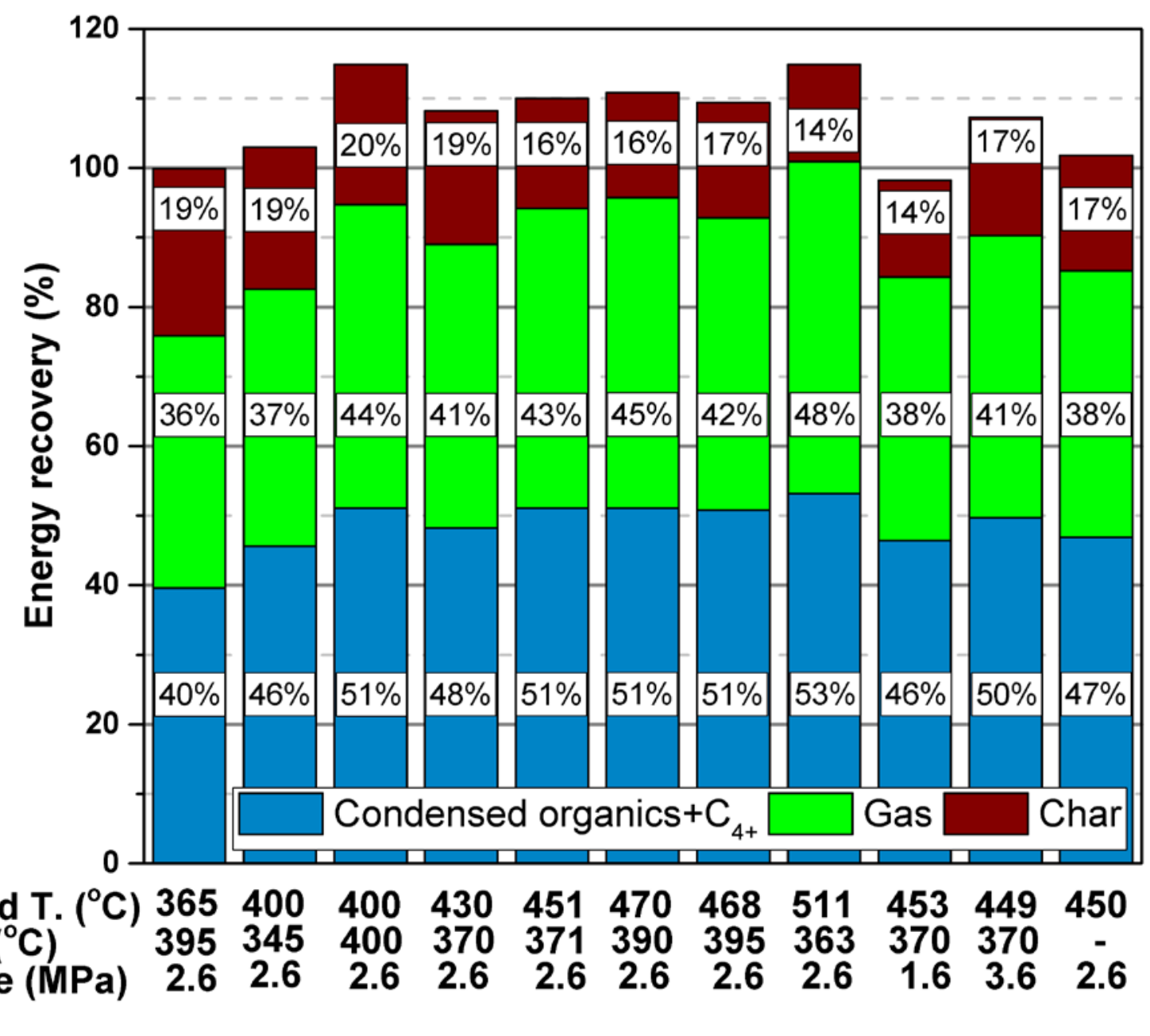

429

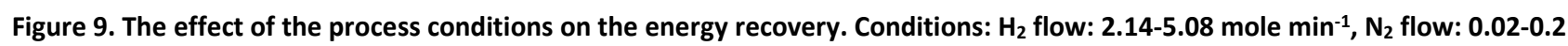
mole $\min ^{-1}$, biomass feeding rate: $159-250 \mathrm{~g} \mathrm{~h}^{-1}, \mathrm{H}_{2} \mathrm{~S}$ concentration: $47-460 \times 10^{-6}$ mole fraction.

Trinh et al. [35] achieved a bio-oil mass yield from fast pyrolysis of wood of $68 \%$ daf, corresponding to an energy recovery of $74 \%$, which is significantly higher than the energy recovery achieved in this study. However, the bio-oil had an oxygen mass fraction of $35.3 \%$ dry basis. Baldauf et al. [36] tested the ability of a commercial CoMoS catalyst to upgrade pyrolysis oil in a fixed bed reactor and showed that it is possible to achieve a degree of deoxygenation of $99.9 \%$ with an oil mass yield of $33 \%$. This shows that a total oil mass yield of $22 \%$ daf and energy recovery of $53 \%$ is possible with fast pyrolysis followed by HDO, which is comparable with the results from experiment 8 . This indicates that catalytic hydropyrolysis is competitive with fast pyrolysis followed by HDO. Furthermore, Baldauf et al. [36] experienced problems with rapid 
catalyst deactivation and operational problems due to the instability and coking potential of the used biooil, which are problems that were not encountered in this study.

441 The produced gas could through steam reforming be used to generate the hydrogen needed in the 442 hydropyrolysis and HDO reactor, as proposed by Marker et al. [2]. The process could also be combined with 443 other renewable energy technologies. For instance, electricity produced from wind turbines could be used 444 to generate the hydrogen needed in the process by electrolysis, and the produced gas could instead be converted fully to substitute natural gas by methanation of $\mathrm{CO}$ and $\mathrm{CO}_{2}$. Since the amount of hydrogen added to the products depend on the applied process conditions the process could be adjusted to correspond to the energy available from excess renewable electricity, resulting in energy storage in the form of liquid and gaseous fuels. Our experimental results confirm and expand on the positive results obtained by Marker et al. [1,2] by a similar combined catalytic hydropyrolysis and downstream hydrotreating process.

\section{Conclusion}

In this work, beech wood was converted into liquid fuels by catalytic hydropyrolysis in a fluid bed reactor with a sulfided $\mathrm{CoMo} / \mathrm{MgAl}_{2} \mathrm{O}_{4}$ catalyst followed by a deep hydrodeoxygenation in a fixed bed reactor with a sulfided $\mathrm{NiMo} / \mathrm{Al}_{2} \mathrm{O}_{3}$ catalyst. The char yield decreased and the gas yield increased with increasing fluid bed temperature, while the condensable organic yield was less affected by the temperature. Increasing the total pressure mainly increased the aqueous phase yield and decreased the $\mathrm{CO}$ and $\mathrm{CO}_{2}$ yield, while only negligible changes in the yields of condensable organics and char yield were observed. Detailed analysis of the condensed organics showed that it consisted of species in the diesel and naphtha boiling point range.

459 The condensed organics had a high concentration of aromatics and the concentration was mainly 460 controlled by the fluid bed temperature and the total pressure. Comparing the experimental results with 461 equilibrium calculations indicated that the aromatic to naphtene ratio was controlled by the 462 thermodynamic equilibrium at high temperatures, but was kinetically controlled at low temperatures. 
When using both reactors the condensed organics were essentially oxygen free. Bypassing the HDO reactor increased the oxygen content in the organics, however, the oxygen content was still significantly lower than the oxygen content in normal pyrolysis oil and the oxygen was mainly different phenols, but minor amounts of oxygenated aliphatics were also observed. Overall, the present experimental results indicate that catalytic hydropyrolysis of biomass may be a viable path to green transportation fuels.

\section{Acknowledgments}

This work is part of the H2CAP project (Hydrogen assisted catalytic pyrolysis for green fuels) conducted at the CHEC research center at The Department of Chemical and Biochemical Engineering at DTU, Denmark. The work was supported by The Danish Council for Strategic Research (now Innovation Fund Denmark, project 1377-00025A), The Programme Commission on Sustainable Energy and Environment. Funding from DTU is also gratefully acknowledged. The authors would also like to thank Research Engineer Nadia Luciw Ammitzbøll (Haldor Topsøe A/S) for fruitful discussions.

\section{References}

[1] T.L. Marker, L.G. Felix, M.B. Linck, M.J. Roberts, Integrated hydropyrolysis and hydroconversion $\left(\mathrm{IH}^{2^{\circ}}\right)$ for the direct production of gasoline and diesel fuels or blending components from biomass, part 1: Proof of principle testing, Environ. Prog. Sustain. Energy. 31 (2012) 191-199. doi:10.1002/ep.10629.

[2] T.L. Marker, L.G. Felix, M.B. Linck, M.J. Roberts, P. Ortiz-Toral, J. Wangerow, Integrated hydropyrolysis and hydroconversion $\left(\mathrm{IH}^{2^{\circ}}\right)$ for the direct production of gasoline and diesel fuels or blending components from biomass, Part 2: Continuous testing, Environ. Prog. Sustain. Energy. 33 (2014) 762-768. doi:10.1002/ep.11906.

[3] F. Bergius, Process for distilling and liquefying coal, US Patent 1,669,439, 1928. 
485 [4] F. Bergius, J. Billwiller, Process for producing liquid or soluble organic combinations from hard coal $486 \quad$ and the like., US Patent 1,251,954, 1918.

487 [5] Friedrich Bergius, Chemical reactions under high pressure, Nobel Lect. (1932) 33.

488 [6] M. Steinberg, P.T. Fallon, M.S. Sundaram, Flash pyrolysis of biomass with reactive and non-reactive 489 gas, Biomass. 9 (1986) 293-315. doi:10.1016/0144-4565(86)90080-6.

[7] D. Meier, R. Ante, O. Faix, Catalytic hydropyrolysis of lignin: Influence of reaction conditions on the 491 formation and composition of liquid products, Bioresour. Technol. 40 (1992) 171-177.

[8] F. Melligan, M.H.B. Hayes, W. Kwapinski, J.J. Leahy, Hydro-pyrolysis of biomass and online catalytic 494 doi:10.1016/0960-8524(92)90205-C.

[9] D.P. Gamliel, L. Wilcox, J.A. Valla, The effects of catalyst properties on the conversion of biomass via catalytic fast hydropyrolysis, Energy \& Fuels. 31 (2017) 679-687. doi:10.1021/acs.energyfuels.6b02781.

[10] S. Thangalazhy-Gopakumar, S. Adhikari, R.B. Gupta, Catalytic pyrolysis of biomass over $\mathrm{H}^{+} \mathrm{ZSM}-5$ under hydrogen pressure, Energy \& Fuels. 26 (2012) 5300-5306. doi:10.1021/ef3008213.

[11] V.K. Venkatakrishnan, W.N. Delgass, F.H. Ribeiro, R. Agrawal, Oxygen removal from intact biomass to produce liquid fuel range hydrocarbons via fast-hydropyrolysis and vapor-phase catalytic hydrodeoxygenation, Green Chem. 17 (2015) 178-183. doi:10.1039/c4gc01746c.

[12] V.K. Venkatakrishnan, J.C. Degenstein, A.D. Smeltz, W.N. Delgass, R. Agrawal, F.H. Ribeiro, Highpressure fast-pyrolysis, fast-hydropyrolysis and catalytic hydrodeoxygenation of cellulose: Production of liquid fuel from biomass, Green Chem. 16 (2014) 792-802. doi:10.1039/c3gc41558a. 
[13] L. Zhang, K. Gong, J. Lai, P. Alvey, Chemical composition and stability of renewable hydrocarbon products generated from a hydropyrolysis vapor upgrading process, Green Chem. 19 (2017) 36283641. doi:10.1039/C7GC01075C.

[14] J. Fan, J. Gephart, T. Marker, D. Stover, B. Updike, D.R. Shonnard, Carbon Footprint Analysis of Gasoline and Diesel from Forest Residues and Corn Stover using Integrated Hydropyrolysis and Hydroconversion, ACS Sustain. Chem. Eng. (2015). doi:10.1021/acssuschemeng.5b01173.

[15] D.C. Dayton, J. Carpenter, J. Farmer, B. Turk, R. Gupta, Biomass hydropyrolysis in a pressurized fluidized bed reactor, Energy \& Fuels. 27 (2013) 3778-3785. doi:10.1021/ef400355t.

[16] D.C. Dayton, J. Hlebak, J.R. Carpenter, K. Wang, O.D. Mante, J.E. Peters, Biomass hydropyrolysis in a fluidized bed reactor, Energy \& Fuels. 30 (2016) 4879-4887. doi:10.1021/acs.energyfuels.6b00373.

[17] K. Wang, D.C. Dayton, J.E. Peters, O.D. Mante, Reactive catalytic fast pyrolysis of biomass to produce high-quality bio-crude, Green Chem. 19 (2017) 3243-3251. doi:10.1039/C7GC01088E.

[18] A.V. Bridgwater, Review of fast pyrolysis of biomass and product upgrading, Biomass and Bioenergy. 38 (2012) 68-94. doi:10.1016/j.biombioe.2011.01.048.

[19] T.A. Milne, A.H. Brenan, B.H. Glenn, Sourcebook of Methods of Analysis for Biomass and Biomass Conversion Processes, Elsevier Applied Science, New York, 1990.

[20] T.M.H. Dabros, A. Gaur, D.G. Pintos, P. Sprenger, M. Høj, T.W. Hansen, F. Studt, J. Gabrielsen, J.-D. Grunwaldt, A.D. Jensen, Influence of $\mathrm{H} 2 \mathrm{O}$ and $\mathrm{H} 2 \mathrm{~S}$ on the composition, activity, and stability of sulfided Mo, CoMo, and NiMo supported on MgAl 204 for hydrodeoxygenation of ethylene glycol, Appl. Catal. A Gen. 551 (2018) 106-121. doi:10.1016/j.apcata.2017.12.008.

[21] P.M. Mortensen, D. Gardini, H.W.P. de Carvalho, C.D. Damsgaard, J.-D. Grunwaldt, P.A. Jensen, J.B. Wagner, A.D. Jensen, Stability and resistance of nickel catalysts for hydrodeoxygenation: Carbon 
deposition and effects of sulfur, potassium, and chlorine in the feed, Catal. Sci. Technol. 4 (2014) 3672-3686. doi:10.1039/c4cy00522h.

[22] V.N. Bui, D. Laurenti, P. Afanasiev, C. Geantet, Hydrodeoxygenation of guaiacol with CoMo catalysts. Part I: Promoting effect of cobalt on HDO selectivity and activity, Appl. Catal. B Environ. 101 (2011) 239-245. doi:10.1016/j.apcatb.2010.10.025.

[23] P. Grange, E. Laurent, R. Maggi, A. Centeno, B. Delmon, Hydrotreatment of pyrolysis oils from biomass: Reactivity of the various categories of oxygenated compounds and preliminary technoeconomical study, Catal. Today. 29 (1996) 297-301. http://www.sciencedirect.com/science/article/pii/0920586195002952.

[24] O.I. Şenol, E.-M. Ryymin, T.-R. Viljava, A.O.I. Krause, Effect of hydrogen sulphide on the hydrodeoxygenation of aromatic and aliphatic oxygenates on sulphided catalysts, J. Mol. Catal. A Chem. 277 (2007) 107-112. doi:10.1016/j.molcata.2007.07.033.

[25] O.i. Şenol, T.-R. Viljava, A.O.I. Krause, Effect of sulphiding agents on the hydrodeoxygenation of aliphatic esters on sulphided catalysts, Appl. Catal. A Gen. 326 (2007) 236-244. doi:10.1016/j.apcata.2007.04.022.

[26] O.I. Şenol, E.-M. Ryymin, T.-R. Viljava, A.O.I. Krause, Reactions of methyl heptanoate hydrodeoxygenation on sulphided catalysts, J. Mol. Catal. A Chem. 268 (2007) 1-8. doi:10.1016/j.molcata.2006.12.006.

[27] C. Bouvier, Y. Romero, F. Richard, S. Brunet, Effect of $\mathrm{H}_{2} \mathrm{~S}$ and $\mathrm{CO}$ on the transformation of 2ethylphenol as a model compound of bio-crude over sulfided Mo-based catalysts: propositions of promoted active sites for deoxygenation pathways based on an experimental study, Green Chem. 13 (2011) 2441-2451. doi:10.1039/c1gc15181a. 
[28] K. Schofield, The enigmatic mechanism of the flame ionization detector: Its overlooked implications for fossil fuel combustion modeling, Prog. Energy Combust. Sci. 34 (2008) 330-350. doi:10.1016/j.pecs.2007.08.001.

[29] M. Garcia-Perez, X.S. Wang, J. Shen, M.J. Rhodes, F. Tian, W.-J. Lee, H. Wu, C.-Z. Li, Fast pyrolysis of oil mallee woody biomass: Effect of temperature on the yield and quality of pyrolysis products, Ind. Eng. Chem. Res. 47 (2008) 1846-1854. doi:10.1021/ie071497p.

[30] T.N. Trinh, P.A. Jensen, Z. Sárossy, K. Dam-Johansen, N.O. Knudsen, H.R. Sørensen, H. Egsgaard, Fast pyrolysis of lignin using a pyrolysis centrifuge reactor, Energy and Fuels. 27 (2013) 3802-3810. doi:10.1021/ef400527k.

[31] N. Bech, M.B. Larsen, P.A. Jensen, K. Dam-Johansen, Modelling solid-convective flash pyrolysis of straw and wood in the pyrolysis centrifuge reactor, Biomass and Bioenergy. 33 (2009) 999-1011. doi:10.1016/j.biombioe.2009.03.009.

[32] T.N. Trinh, P.A. Jensen, K. Dam-Johansen, N.O. Knudsen, H.R. Sørensen, Influence of the pyrolysis temperature on sewage sludge product distribution, bio-oil, and char properties, Energy \& Fuels. 27 (2013) 1419-1427. doi:10.1021/ef301944r.

[33] T. Lang, A.D. Jensen, P.A. Jensen, Retention of organic elements during solid fuel pyrolysis with emphasis on the peculiar behavior of nitrogen, Energy and Fuels. 19 (2005) 1631-1643. doi:10.1021/ef049739a.

[34] W.G. Lloyd, D.A. Davenport, Applying thermodynamics to fossil fuels: Heats of combustion from elemental compositions, J. Chem. Educ. 57 (1980) 56. doi:10.1021/ed057p56.

[35] T.N. Trinh, P.A. Jensen, K. Dam-Johansen, N.O. Knudsen, H.R. Sørensen, S. Hvilsted, Comparison of lignin, macroalgae, wood, and straw fast pyrolysis, Energy \& Fuels. 27 (2013) 1399-1409. 
doi:10.1021/ef301927y.

574 [36] W. Baldauf, U. Balfanz, M. Rupp, Upgrading of flash pyrolysis oil and utilization in refineries, Biomass

575

576 and Bioenergy. 7 (1994) 237-244. http://linkinghub.elsevier.com/retrieve/pii/0961953494000652 (accessed January 18, 2016).

578 Supplementary material

579 Masse balances on elemental basis

580 An overview of the carbon, hydrogen and oxygen recovery is shown in Table S.1.

Table S.1. Mass balances on elemental basis for carbon, hydrogen and oxygen

\begin{tabular}{lrrrrrrrrrrr}
\hline Test & $\mathbf{1}$ & $\mathbf{2}$ & $\mathbf{3}$ & $\mathbf{4}$ & $\mathbf{5}$ & $\mathbf{6}$ & $\mathbf{7}$ & $\mathbf{8}$ & $\mathbf{9}$ & $\mathbf{1 0}$ & $\mathbf{1 1}$ \\
\hline Carbon recovery (\%) & & & & & & & & & & \\
$\mathrm{C}_{1}-\mathrm{C}_{3}$ & 21.5 & 19.7 & 23.1 & 22.9 & 21.6 & 19.4 & 22.5 & 24.3 & 18.9 & 20.7 & 19.0 \\
$\mathrm{C}_{4+}$ & 14.2 & 16.8 & 18.9 & 16.9 & 14.5 & 14.4 & 15.1 & 18.8 & 14.4 & 17.1 & 13.9 \\
$\mathrm{CO}_{+} \mathrm{CO}_{2}$ & 11.4 & 9.3 & 10.1 & 12.7 & 12.5 & 8.2 & 12.1 & 12.7 & 13.3 & 10.3 & 12.6 \\
Char & 20.9 & 21.0 & 22.0 & 17.3 & 18.2 & 26.4 & 17.2 & 15.5 & 15.5 & 18.9 & 18.4 \\
Organics & 19.9 & 15.1 & 17.2 & 20.3 & 22.6 & 13.6 & 21.4 & 19.6 & 19.4 & 18.6 & 20.9 \\
Aqueous phase & 0.0 & 0.0 & 0.0 & 0.0 & 0.0 & 0.0 & 0.0 & 0.0 & 0.0 & 0.0 & 0.6 \\
Sum & 87.9 & 82.0 & 91.3 & 90.1 & 89.5 & 82.0 & 88.4 & 90.9 & 81.4 & 85.5 & 85.4 \\
\hline Hydrogen recovery (\%) & & & & & & & & & & \\
$\mathrm{C}_{1}-\mathrm{C}_{3}$ & 48.3 & 44.1 & 51.7 & 52.0 & 49.0 & 43.3 & 50.7 & 55.3 & 42.8 & 46.8 & 43.0 \\
$\mathrm{C}_{4+}$ & 24.0 & 28.3 & 31.8 & 28.4 & 24.5 & 24.3 & 25.5 & 31.6 & 24.2 & 28.7 & 23.3 \\
CO+CO & 0.0 & 0.0 & 0.0 & 0.0 & 0.0 & 0.0 & 0.0 & 0.0 & 0.0 & 0.0 & 0.0 \\
Char & 9.2 & 9.7 & 9.9 & 6.8 & 7.6 & 13.3 & 7.3 & 5.8 & 6.7 & 7.9 & 7.3 \\
Organics & 23.7 & 17.8 & 19.1 & 21.6 & 25.0 & 15.1 & 24.3 & 20.2 & 20.5 & 20.5 & 20.4 \\
Aqueous phase & 66.5 & 70.2 & 66.8 & 67.1 & 67.2 & 58.0 & 65.7 & 66.5 & 62.0 & 70.4 & 69.1 \\
Sum & 171.8 & 170.3 & 179.3 & 175.8 & 173.3 & 153.9 & 173.5 & 179.4 & 156.2 & 174.3 & 163.1 \\
\hline Oxygen recovery (\%) & & & & & & & & & & \\
$\mathrm{C}_{1}-\mathrm{C}_{3}$ & 0.0 & 0.0 & 0.0 & 0.0 & 0.0 & 0.0 & 0.0 & 0.0 & 0.0 & 0.0 & 0.0 \\
$\mathrm{C}_{4+}$ & 0.0 & 0.0 & 0.0 & 0.0 & 0.0 & 0.0 & 0.0 & 0.0 & 0.0 & 0.0 & 0.0 \\
CO+CO$_{2}$ & 24.2 & 19.7 & 20.2 & 25.1 & 25.7 & 16.5 & 25.3 & 23.7 & 26.6 & 18.4 & 24.0 \\
Char & 6.9 & 7.5 & 7.3 & 5.1 & 5.0 & 9.8 & 5.0 & 3.0 & 6.1 & 6.0 & 5.4 \\
Organics & 0.0 & 0.0 & 0.0 & 0.0 & 0.0 & 0.0 & 0.0 & 0.0 & 0.0 & 0.0 & 0.0 \\
Aqueous phase & 72.3 & 76.4 & 72.7 & 73.0 & 73.1 & 63.0 & 71.4 & 72.3 & 67.5 & 76.5 & 75.1 \\
Sum & 103.4 & 103.5 & 100.2 & 103.2 & 103.8 & 89.3 & 101.7 & 99.0 & 100.2 & 100.9 & 104.5 \\
\hline
\end{tabular}


584 The effect of bypassing the HDO reactor is shown in Figure S.1, where the simulated distillation curve for experiment 7 and 11 are shown. Bypassing the HDO reactor clearly increases the final boiling point of the condensed organics; this is most likely due to the increase in the oxygen content. The effect of the temperature and pressure on the simulated distillation curve is shown in Figure S.1 B and Figure S.1 C. Increasing the fluid bed temperature decreases the final boiling point, this is because more cracking takes place at higher temperatures. No significant effect of varying the pressure on the distillation curve is 590 observed.
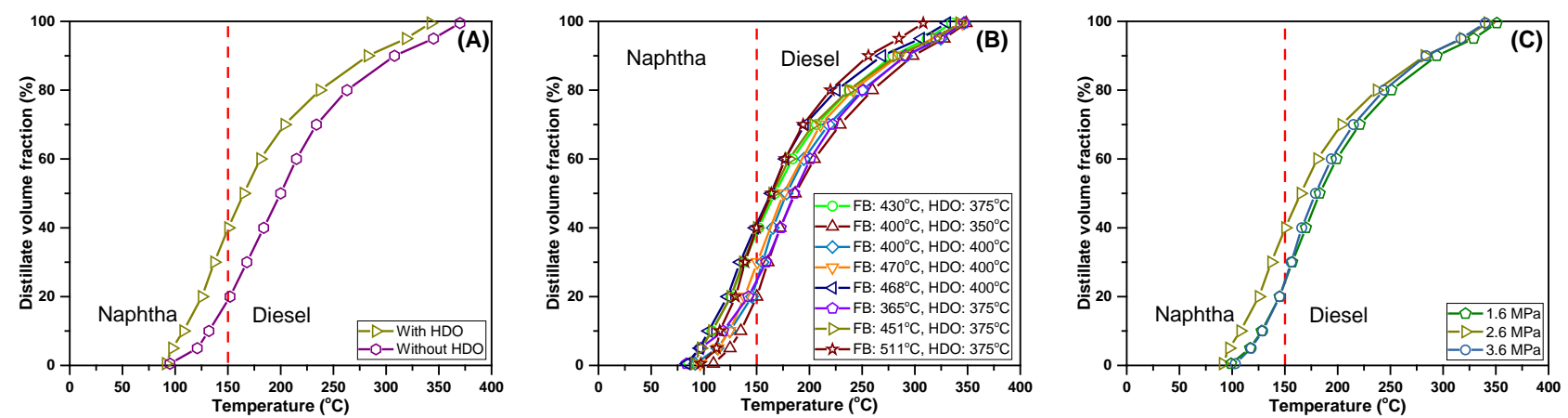

Figure S.1. GC simulated distillation curves for the condensed organics with and without HDO reactor (A), at different fluid bed and HDO reactor tempereatures (B), and different total pressure (C). The curves are calculated using D86 according to ASTM D 7213 C.

\section{Equilibrium calculations}

Equilibrium concentrations were calculated using the HSC Chemistry 9 software package. GCXGC-MS shows that the produced oil is a very complex mixture and in our calculations we have therefore on the basis of the results from GCXGC-MS reduced the amount of hydrocarbons to 9 (shown in Figure S.2).<smiles>Cc1ccccc1</smiles>

Toluene

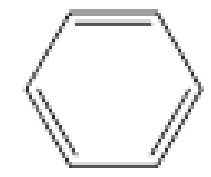

benzene<smiles>c1ccc2ccccc2c1</smiles>

naphthalene<smiles>Cc1ccccc1C</smiles>

o-xylene

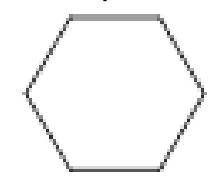

cyclohexane<smiles>c1ccc2c(c1)CCCC2</smiles>

1,2,3,4-tetrahydronaphthalene<smiles>CC1CCCCC1C</smiles>

1,2-dimethylcyclohexane<smiles>CC1CCCCC1</smiles>

methylcyclohexane<smiles>C[C@]12CCCC[C@@]1(C)CCCC2</smiles>

decahydronapthalene

Figure S.2 . Model compounds used to calculate equilibrium concentrations

The used initial molar distribution is shown in Table S.2. 


\begin{tabular}{lc}
\hline & Hydrogen free mole fraction \\
\hline Benzene + cyclohexane & $20 \%$ \\
Toluene + methylcyclohexane & $20 \%$ \\
o-xylene $+1,2$-dimethylcyclohexane & $20 \%$ \\
Naphthalene+ $1,2,3,4$-tetrahydronaphthalene +decahydronapthalene & $40 \%$ \\
\hline The equilibrium concentration of the molecules as a function of temperature at different hydrogen partial \\
pressures is shown in Figure $\mathrm{S} .3$. The naphthenes are favored at lower temperature. At temperatures above \\
approximately $405{ }^{\circ} \mathrm{C}$ at $99 \% \mathrm{H}_{2}$ the monoaromatics become the main components. When the hydrogen \\
partial pressure is increased the naphthenes becomes more dominating. The fraction of diaromatics is close \\
to zero at temperatures below $450{ }^{\circ} \mathrm{C}$ and when the gas consists of $99 \%$ hydrogen.
\end{tabular}

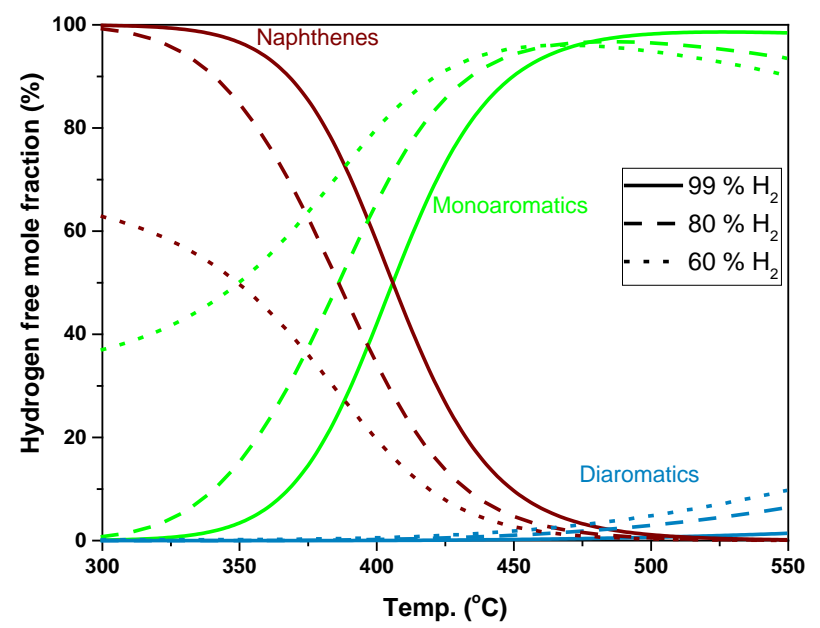

Figure S.3. The influence of temperature and hydrogen partial pressure on the equilibrium distribution between the molecules shown in Figure S.2. The calculations were conducted in HSC Chemistry 9 at $2.5 \mathrm{MPa}$.

The effect of varying the total pressure on naphthenes, monoaromatics, and diaromatics is shown in Figure S.4. The aromatics are more thermodynamically favored at a low total pressure. The monoaromatics have a maximum at 0.5 to $1 \mathrm{MPa}$. The concentration of diaromatics decreases with the total pressure and is close to zero when the pressure increases to above $1 \mathrm{MPa}$. The reason for the peak in monoaromatics is that at low pressure naphthalene is more equilibrium favorable than 1,2,3,4-tetrahydronaphthalene. 


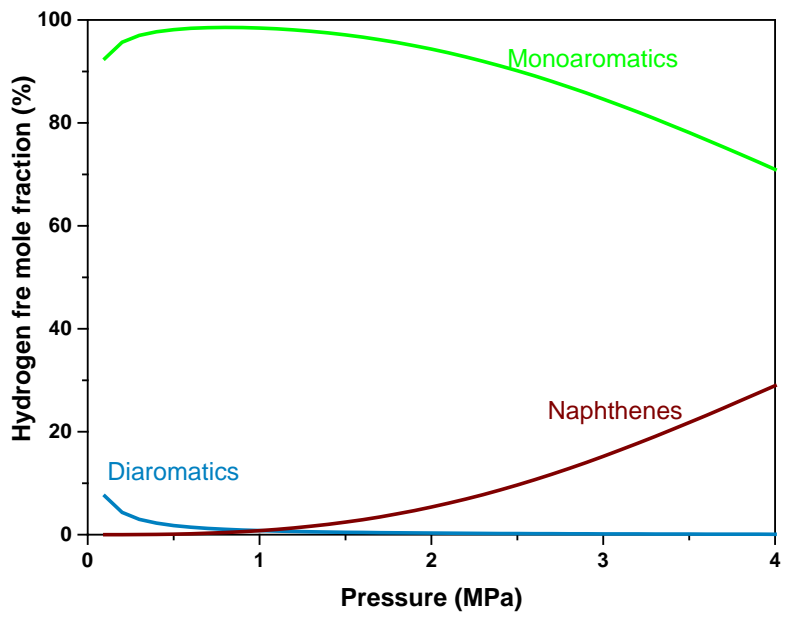

Figure S.4. The influence of the total pressure on the equilibrium distribution between the molecules shown in Figure S.2. The calculations were conducted in $\mathrm{HSC}$ Chemistry 9 at $4500^{\circ} \mathrm{C}$ with $99 \% \mathrm{H}_{2}$ in the gas.

\section{Chromatograms}

The chromatograms for GC-AED on the condensed oil from experiment 7 and 11 are shown in Figure S.5. In (ISTD) and 4-fluoro-phenol was used as ISTD in the analysis of the condensed organics from experiment 11.
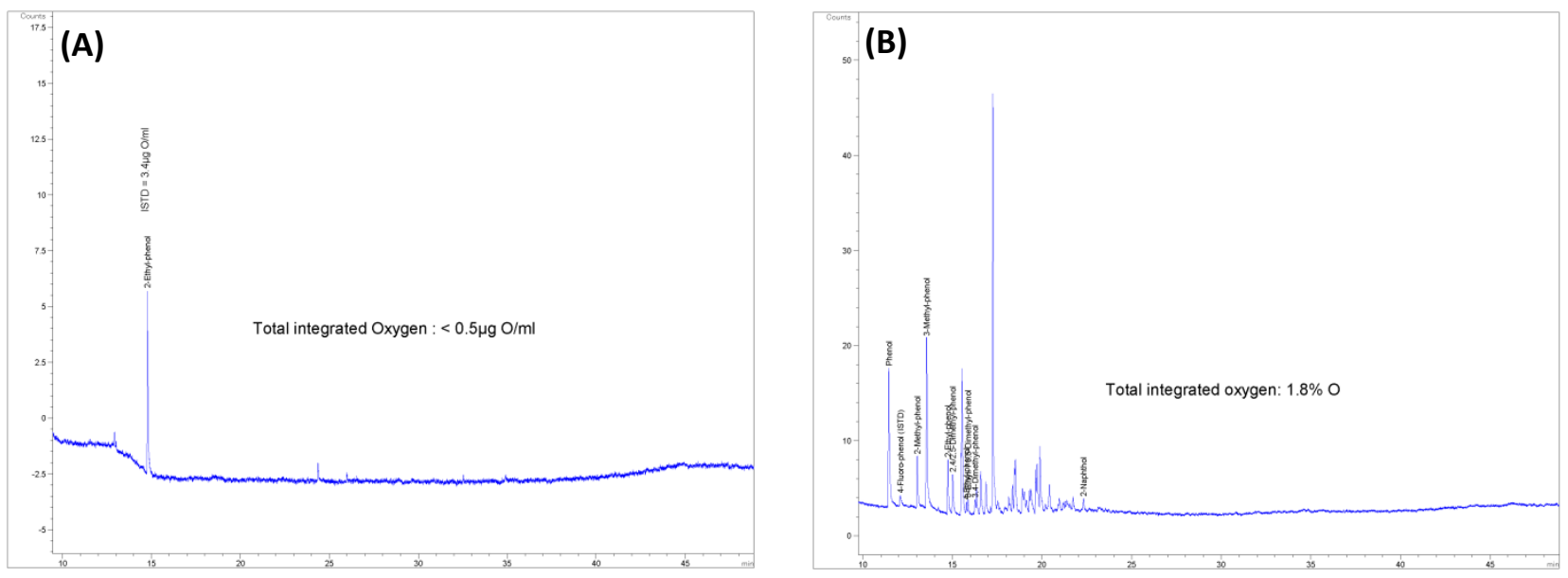

Figure S.5. Chromatograms for GC-AED of the condensed oil in experiment 7 (A) and experiment 11 (B). Conditions: Fluid bed temperature: $450{ }^{\circ} \mathrm{C}$, $\mathrm{HDO}$ temperature in experiment $7: 371^{\circ} \mathrm{C}$, the HDO reactor was bypassed in experiment 11, pressure: 2.6 $\mathrm{MPa}, \mathrm{H}_{2}$ flow: 82-87.4, $\mathrm{N}_{2}$ flow: 0.62-5 NL/min, biomass feeding rate: $174-250 \mathrm{~g} / \mathrm{h}, \mathrm{H}_{2} \mathrm{~S}$ concentration: 48-460 ppm.

\section{Retention of organic Elements in the char}

625 The retention of the elements is defined as:

626 Retention $=\frac{\text { element } w t . \% \text { daf in char }}{\text { element } w t . \% \text { daf in beech wood }} \times$ char yield $w t . \%$ daf

627 The retention of nitrogen, carbon, hydrogen and oxygen is shown in Figure S.6. 

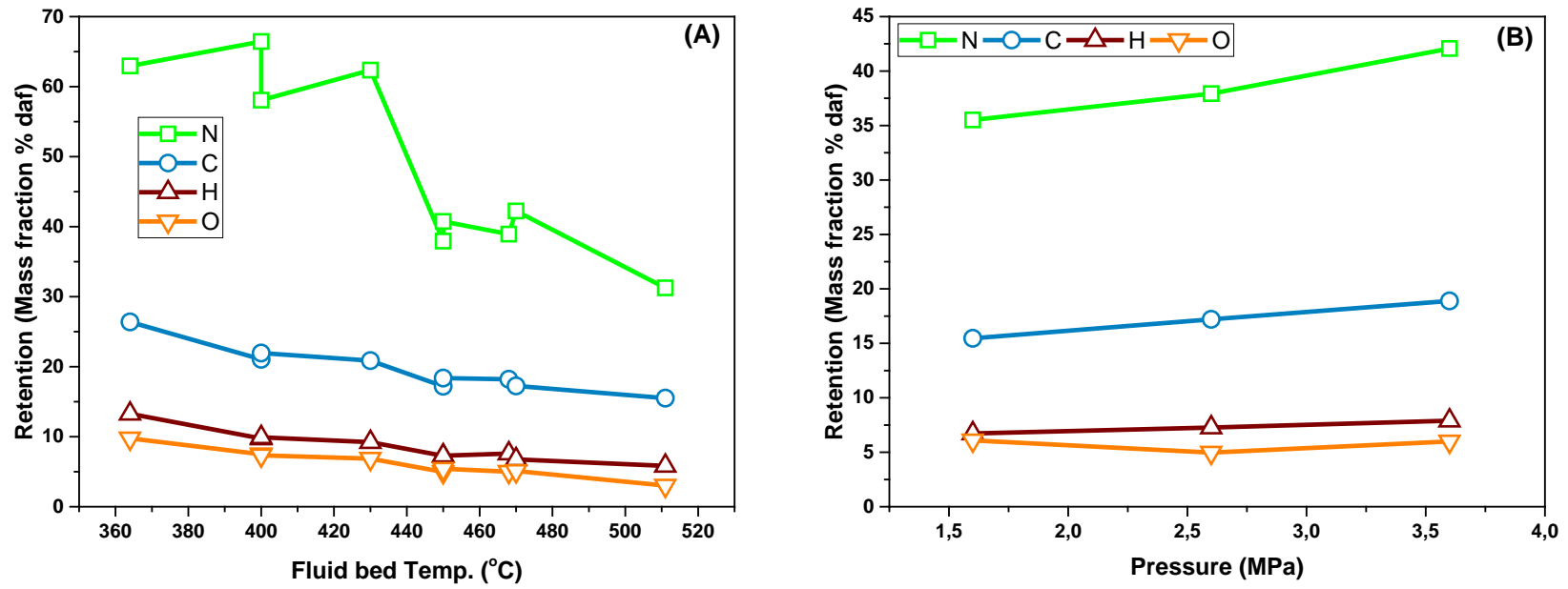

Figure S.6. Retention of nitrogen, carbon, hydrogen, and oxygen as a function fluid bed temperature (A) and pressure (B). Conditions: $\mathrm{H}_{2}$ flow: $2.14-5.08 \mathrm{~mole} / \mathrm{min}, \mathrm{N}_{2}$ flow: 0.02-0.2 mole/min, biomass feeding rate: $159-300 \mathrm{~g} / \mathrm{h}, \mathrm{H}_{2} \mathrm{~S}$ concentration: 0.47-4.6 $\times 10^{-3}$ mole fraction.

\section{Gas residence time in setup}

632 The vapor residence time in the different parts of the setup is shown in Table S.3. The first condenser was

633 located directly after the HDO reactor, thus the residence time between these two is below $1 \mathrm{~s}$.

Table S.3. Vapor residence time in setup

\begin{tabular}{lc}
\hline & Residence time \\
\hline Flow screw feeder to fluid bed & $\sim 2 \mathrm{~s}$ \\
Fluid bed reaction zone & $\sim 1 \mathrm{~s}$ \\
Fluid bed disengagement zone & $\sim 2 \mathrm{~s}$ \\
Pipes between fluid bed, filter and HDO reactor & $<1 \mathrm{~s}$ \\
Filter & Up to $16 \mathrm{~s}$ \\
HDO reactor & $\sim 2 \mathrm{~s}$ \\
\hline
\end{tabular}

